Bull. Mater. Sci., Vol. 20, No. 6, September 1997, pp. 845-878. C Printed in India.

\title{
Monte Carlo and molecular dynamics simulation of argon clusters and $n$-alkanes in the confined regions of zeolites ${ }^{\dagger}$
}

\author{
CHITRA RAJAPPA, SANJOY BANDYOPADHYAY and YASHONATH \\ SUBRAMANIAN** \\ Solid State and Structural Chemistry Unit, ${ }^{\ddagger}$ Also at Supercomputer Education and Research \\ Centre, Indian Institute of Science, Bangalore 560012 , India
}

\begin{abstract}
Geometry and energy of argon clusters confined in zeolite $\mathrm{NaCaA}$ are compared with those of free clusters. Results indicate the possible existence of magic numbers among the confined clusters. Spectra obtained from instantaneous normal mode analysis of free and confined clusters give a larger percentage of imaginary frequencies for the latter indicating that the confined cluster atoms populate the saddle points of the potential energy surface significantly. The variation of the percentage of imaginary frequencies with temperature during melting is akin to the variation of other properties. It is shown that confined clusters might exhibit inverse surface melting, unlike medium-to-large-sized free clusters that exhibit surface melting. Configurational-bias Monte Carlo (CBMC) simulations of $n$-alkanes in zeolites $\mathrm{Y}$ and $\mathrm{A}$ are reported. CBMC method gives reliable estimates of the properties relating to the conformation of molecules. Changes in the conformational properties of $n$-butane and other longer $n$-alkanes such as $n$-hexane and $n$-heptane when they are confined in different zeolites are presented. The changes in the conformational properties of $n$-butane and $n$-hexane with temperature and concentration is discussed. In general, in zeolite $Y$ as well as $\mathrm{A}$, there is significant enhancement of the gauche population as compared to the pure unconfined fluid
\end{abstract}

Keywords. Argon clusters; $n$-alkanes; zeolites; Monte Carlo; molecular dynamics.

\section{Introduction}

Clusters exhibit properties different from those of individual atoms or molecules as well as that of bulk. The study of clusters is not only interesting for its own sake but also because it can provide insight into the transition from the individual to the bulk behaviour (Nauchitel and Pertsin 1980; Honeycutt and Andersen 1987; Berry and Cheng 1992). One of the characteristic features of clusters of small sizes $(\approx 5-100$ atoms or molecules) is that their properties do not vary smoothly with the cluster size, $n$. Clusters of certain sizes seem to be significantly stabler than the neighbouring sizes - these values of $n$ are termed magic numbers (Hoare and Pal 1970; Frantz 1995). The properties of free clusters get significantly altered when they are confined in a host matrix. The extent to which a specific property will be altered would depend on the nature of the confining medium. Our aim here is to consider two specific, though somewhat unconnected systems: (i) argon clusters confined in zeolites $\mathrm{NaCaA}$ and $\mathrm{L}$, and (ii) alkanes $\left(\mathrm{C}_{4}\right.$ to $\mathrm{C}_{8}$ and $\left.\mathrm{C}_{10}\right)$ in zeolites $\mathrm{Y}$ and $\mathrm{A}$. We shall see how the properties of free argon clusters such as

Contribution No. 1260 from the Solid State and Structural Chemistry Unit

*Author for corresponiknci 
structure, energetics, dynamics and melting behaviour are modified when they are confined in zeolitic cages. Instantaneous normal mode analysis (Adams and Stratt 1990a) of the free and confined clusters are also presented.

The study of the adsorption and conformational properties of long chain $n$-alkane molecules in zeolites is relevant to many practical applications and is interesting from a theoretical point of view. A proper investigation of the conformational behaviour of flexible alkane molecules within the zeolite is essential to understand other properties. Many experiments have been attempted to determine the sorption behaviour of alkanes in zeolites (Richards and Rees 1987; Thamm 1987). But it is difficult to obtain experimentally the behaviour of adsorbed molecules at a molecular level. Only recently NMR techniques have been used to study the adsorption and diffusion in zeolites (Chmelka et al 1991; Karger and Ruthven 1992). PFG NMR has been used to study the self-diffusion of $n$-alkanes from methane to $n$-heptane in zeolites $\mathrm{NaCaA}$ and $\mathrm{NaX}$ (Karger et al 1980; Heink et al 1992). But detailed information on the conformational behaviour of industrially important long-chain $n$-alkanes is not available.

Molecular simulation methods enable one to study the adsorption, diffusion and conformational properties of long chain molecules. These methods have been used by Theodorou and coworkers (June et al 1990, 1992) to study the conformations of $n$-butane and $n$-hexane in silicalite at different sorbate loadings. Recently, adsorption of $n$-alkanes, ranging from butane to dodecane has been studied in silicalite and mordenite at zero coverage limit by Smit and Siepmann (1994a). Thermodynamics, conformational and diffusion related properties of $n$-butane and $n$-hexane in silicalite have been studied in detail by Hernandez and Catlow (1995) using molecular dynamics (MD) technique. Recently Theodorou and coworkers (Maginn et al 1995) have reported adsorption of $n$-alkanes, ranging from $C_{4}$ to $C_{25}$ in silicalite, using a bias $\mathrm{MC}$ technique. We shall see how the conformational properties of $n$-alkanes are altered on confinement. Calculations have been performed which attempt to obtain the underlying reasons for these differences.

\section{Model}

Structural details of the host zeolites as well as details of the potential parameters are given below for studies pertaining to both argon clusters and $n$-alkane molecules in zeolites.

\subsection{Structural details}

We have carried out $\mathrm{MC}$ simulations of $\mathrm{Ar}_{6}, \mathrm{Ar}_{7}$ and $\mathrm{Ar}_{13}$ clusters confined to the $\alpha$-cages in zeolite $\mathrm{NaCaA}$. We have also studied the melting behaviour of an $\mathrm{Ar}_{13}$ cluster confined in zeolite L. n-alkanes in zeolites $\mathrm{Y}$ and $\mathrm{A}$ have been investigated.

2.1a Zeolite NaCaA: The structure of zeolite NaCaA was taken from the work of Pluth and Smith (1980). Zeolite $\mathrm{NaCaA}$ crystallizes in the cubic space group $F m \overline{3} c$ and has an edge length of $24.555 \AA$. Each unit cell of zeolite NaCaA contains $192 \mathrm{Si}, 384 \mathrm{O}, 32 \mathrm{Na}$ and $32 \mathrm{Ca}$ atoms. There are eight large cavities of about 
$11.4 \AA$ in diameter in every unit cell - these are termed $\alpha$-cages. Each $\alpha$-cage is octahedrally connected to six other $\alpha$-cages via 8 -ring windows with diameters $\sim 4.5 \AA$.

2.1b Zeolite NaY: Zeolite $\mathrm{Y}$ belongs to $F d \overline{3} m$ space group. The structure was taken from the neutron diffraction studies of Fitch et al (1986). The cubic unit cell has an edge length of $24.85 \AA$ and consists of $144 \mathrm{Si}, 48 \mathrm{Al}, 384 \mathrm{O}$ and 48 $\mathrm{Na}$ atoms, corresponding to a $\mathrm{Si} / \mathrm{Al}$ ratio of 3 . The sodium atoms occupy all the SI and SII sites completely and there is zero occupancy of the SIII sites for this ratio of $\mathrm{Si} / \mathrm{Al}$ and, hence, there is no partial occupancy associated with any of the sites. The network of voids in this zeolite consists of eight $\alpha$-cages (each of which is $\sim 11.8 \AA$ in diameter) in one unit cell. Every $\alpha$-cage is tetrahedrally interconnected with four other cages via 12 -membered rings of approximate diameter $7.4 \AA$.

2.1c Zeolite L: The structure of zeolite $\mathrm{L}$ was taken from recent high-resolution neutron powder diffraction studies of Wright et al (1985). The zeolite belongs to the $P 6 / \mathrm{mmm}$ space group with $a=18.6673 \AA$ and $c=7.4956 \AA$. This zeolite has a structure consisting of channels along the c-direction. Each channel is made up of cage-like units interconnected by 12 -membered rings. Consecutive 12-rings are separated by a distance of $7.5 \AA$ along the $c$-direction. The channel is widest (diameter $\sim 13 \AA$ ) midway between the two 12-rings.

Figure 1 shows an $\alpha$-cage in each of zeolites $\mathrm{NaCaA}$ and $\mathrm{NaY}$, as well as one of the cage-like units that constitute the channels in zeolite L.

\subsection{Intermolecular potentials}

2.2a Argon clusters in ceolites: Interactions between the argon atoms in the cluster was modelled by a simple $(6,12)$ Lennard-Jones potential:

$$
\phi(r)=4 \varepsilon\left[(\sigma / r)^{12}-(\sigma / r)^{6}\right]
$$

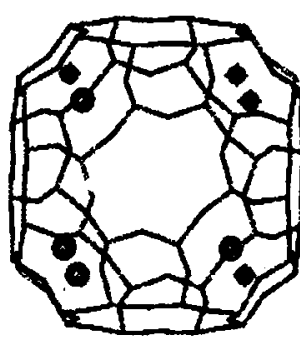

(a)

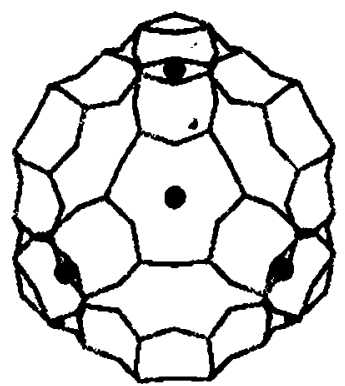

(b)

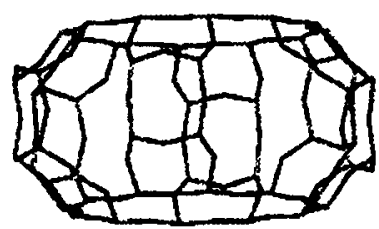

(c)

Figure 1. (a) A single ce-cage of zeolite NaCaA has been shown. (b) A single et-cage in zeolite $\mathrm{NaY}$ is shown. (c) One of the cage-like units that make up the channels in zeolite $\mathrm{L}$ is shown in the figure. 
where $r$ denotes the interatomic separation. $\varepsilon$ and $\sigma$ are, respectively, the well depth and the diameter of the interacting atoms. In the present calculation, we have taken the values of $\sigma$ and $\varepsilon$ from the work of Davis et al (1987).

The total guest-guest interaction energy, i.e. the total interaction between the cluster atoms, is the sum over all such interactions:

$$
U_{\mathrm{gg}}=\frac{1}{2} \sum_{i=1}^{N} \sum_{j=1, j \neq i}^{N} \phi\left(r_{i j}\right)=\frac{1}{2} \sum_{i=1}^{N} u_{\mathrm{gg}}\left(r_{i}\right),
$$

where $i$ and $j$ denote cluster atoms.

The atoms of the cluster also interact with the atoms of the confining zeolite lattice. In the case of a rare-gas cluster confined in zeolite $\mathrm{NaCaA}$, the $\mathrm{Ar}$ atoms are assumed to interact only with the $\mathrm{O}, \mathrm{Na}$ and $\mathrm{Ca}$ atoms of the zeolits framework. In the case of $\mathrm{Ar}_{13}$, confined to zeolite $\mathrm{L}$, the cluster atoms interact with the $\mathrm{O}$ atoms of the zeolite lattice. In both cases, we neglect the interaction of the cluster atoms with the $\mathrm{Si}$ and $\mathrm{Al}$ atoms, since they are effectively screened by the bulkier oxygen atoms. These interactions of a cluster atom with a zeolite atom were also taken to be of the $(6,12)$ Lennard-Jones form: $\phi_{i z}\left(r_{i z}\right)$, where $i$ is a cluster atom and $z=\mathrm{O}$ for zeolite $\mathrm{L}$ and $z=\mathrm{O}, \mathrm{Na}$ or $\mathrm{Ca}$ for zeolite $\mathrm{NaCaA}$. The total cluster-zeolite interaction energy is therefore given by

$$
U_{\mathrm{gh}}=\sum_{i=1}^{N} \sum_{z} \phi\left(r_{i z}\right)=\sum_{i=1}^{N} u_{\mathrm{gh}}\left(r_{i}\right) .
$$

The self-interaction parameters for the zeolite atoms in $\mathrm{NaCaA}$ were taken from Kiselev and Du (1981) and from Inglesfield (1982). For zeolite L, the self-interaction parameters for the $\mathrm{O}-\mathrm{O}$ interaction have been calculated from the work of Henson et al (1993). The cluster atom-zeolite interaction parameters were then calculated using the Lorentz-Berthelot combination rules (Allen and Tildesley 1987).

Both the guest-guest and guest-zeolite potentials were shifted so as to have zero energy at the cut-off radius. The total potential energy of the system is the sum of the contributions from the guest-guest and guest-zeolite interactions,

$$
U=U_{\mathrm{gg}}+U_{\mathrm{gh}}
$$

The potential parameters for all interactions are listed in table 1 .

2.2b n-butane in zeolites: (i) Intramolecular interactions: Alkane molecules have been modelled in terms of united-atom interaction sites or beads, i.e. methyl $\left(\mathrm{CH}_{3}\right)$ and methylene $\left(\mathrm{CH}_{2}\right)$ groups are represented as single interaction centres, each with appropriate mass of 15 or $14 \mathrm{~g} \mathrm{~mol}^{-1}$ and the site of interaction coinciding with position of the $\mathrm{C}$ atom. The distance between these interaction sites is assumed to be the same as the $\mathrm{C}-\mathrm{C}$ bond lengths viz. 1.53 $\AA$. This model has been found to be successful in modelling $n$-butanes (Smit and Siepmann 1994a; Hernandez and Catlow 1995; Maginn et al 1995). Bond bending interactions between three adjacent sites are modelled in terms of a harmonic potential (Van der Ploeg and Berendsen 1982) 


$$
\phi_{\mathrm{b}}(\theta)=\frac{1}{2} k_{\theta}\left(\theta-\theta_{0}\right)^{2}
$$

where $\theta_{0}$ is the equilibrium bond angle of $114^{\circ}$ and the force constant $k_{\theta}=6.25 \times 10^{4} \mathrm{~K} \mathrm{rad}^{-2}$. A torsional potential, governing rotation about non-terminal bonds is expressed in terms of a model proposed by Jorgensen et al (1984)

$$
\phi_{1}(\phi)=a_{1}(1+\cos \phi)+a_{2}(1+\cos 2 \phi)+a_{3}(1+\cos 3 \phi) \text {. }
$$

with $a_{1}=355.03 \mathrm{~K}, a_{2}=-68.19 \mathrm{~K}, a_{3}=-791.32 \mathrm{~K}$. For alkane molecules longer than butane, the sites belonging to the same molecule, which are separated by more than three bonds, interact with each other through $(6,12)$ Lennard-Jones potential

$$
\phi_{\mathrm{nb}}\left(r_{\mathrm{ss}}^{\mathrm{nb}}\right)=4 \varepsilon_{\mathrm{ss}}\left[\left(\frac{\sigma_{\mathrm{ss}}}{r_{\mathrm{ss}}^{\mathrm{nb}}}\right)^{12}-\left(\frac{\sigma_{\mathrm{ss}}}{r_{\mathrm{ss}}^{\mathrm{nb}}}\right)^{6}\right]
$$

Table 1. Potential parameters for guest-guest and guest-zeolite interactions for Ar clusters in zeolites.

\begin{tabular}{lll}
\hline Type & $\begin{array}{c}\sigma \\
(\AA)\end{array}$ & $\begin{array}{c}\varepsilon \\
(\mathrm{kJ} / \mathrm{mol})\end{array}$ \\
\hline Ar-Ar & 3.4 & 1.00568 \\
& & \\
For clusters confined in zeolite NaCaA: & 3.095 & 1.33038 \\
Ar-O & 3.33 & 0.29920 \\
Ar-Na & 3.375 & 3.09831 \\
Ar-Ca & & \\
For clusters confined in zeolite L: & 2.96785 & 1.22469 \\
\hline Ar-O
\end{tabular}

Table 2a. Self-interaction parameters for $n$-alkane molecules.

\begin{tabular}{lcc}
\hline Type & $\sigma(\AA)$ & $\varepsilon(\mathrm{K})$ \\
\hline $\mathrm{CH}_{3}-\mathrm{CH}_{3}$ & 3.93 & 114 \\
$\mathrm{CH}_{2}-\mathrm{CH}_{2}$ & 3.93 & 47 \\
\hline
\end{tabular}

Table 2b. Potential parameters for sorbate-zeolite interactions for $n$-alkane molecules in zeolites.

\begin{tabular}{lcc}
\hline Type & $\begin{array}{c}A_{\mathrm{s},} \\
\left(10^{3} \mathrm{~kJ} / \mathrm{mol} \AA^{6}\right)\end{array}$ & $\begin{array}{c}B_{\mathrm{s} f} \\
\left(10^{6} \mathrm{~kJ} / \mathrm{mol} \AA^{12}\right)\end{array}$ \\
\hline $\mathrm{CH}_{3}-\mathrm{O}$ & 5.0898 & 5.8592 \\
$\mathrm{CH}_{3}-\mathrm{Na}$ & 1.8230 & 4.3085 \\
$\mathrm{CH}_{2}-\mathrm{O}$ & 3.2681 & 3.7622 \\
$\mathrm{CH}_{2}-\mathrm{Na}$ & 1.1705 & 2.7664 \\
\hline
\end{tabular}


The self-interaction parameters of $n$-butane molecules used in the present study were taken from the work of Smit and Siepmann (1994a) and are listed in table 2a. The cross-interaction parameters between $\mathrm{CH}_{3}$ and $\mathrm{CH}_{2}$ groups are obtained from the well-known Lorentz-Berthelot combination rules (Allen and Tildesley 1987).

(ii) Intermolecular interactions: The intermolecular site-site interactions between $n$-butane molecules are modelled in terms of united-atom model consisting of site-site pairwise interactions of the $(6,12)$ Lennard-Jones form given by:

$$
\phi_{\mathrm{ss}}\left(r_{\mathrm{ss}}\right)=4 \varepsilon_{\mathrm{ss}}\left[\left(\frac{\sigma_{\mathrm{ss}}}{r_{\mathrm{ss}}}\right)^{12}-\left(\frac{\sigma_{\mathrm{ss}}}{r_{\mathrm{ss}}}\right)^{6}\right]
$$

The parameters used are the same as those listed in table $2 \mathrm{a}$.

(iii) Sorbate-zeolite interactions: The sorbate-zeolite interactions $\phi_{\mathrm{sz}}\left(r_{\mathrm{sz}}\right)$ are modelled in terms of pairwise $(6,12)$ Lennard-Jones form

$$
\phi_{\mathrm{sz}}\left(r_{\mathrm{sz}}\right)=4 \varepsilon_{\mathrm{sz}}\left[\left(\frac{\sigma_{\mathrm{sz}}}{r_{\mathrm{sz}}}\right)^{12}-\left(\frac{\sigma_{\mathrm{sz}}}{r_{\mathrm{sz}}}\right)^{6}\right],
$$

with interaction parameters $\sigma_{\mathrm{sz}}$ and $\varepsilon_{\mathrm{sz}}$, between the united atoms $s=\mathrm{CH}_{3}$ or $\mathrm{CH}_{2}$ and zeolite atoms $z=\mathrm{O}$, Na. Interactions between the sorbate molecule and the tramework Si/Al atoms are not included since the close approach of the sorbates is prevented by the surrounding bulkier oxygens. The self-interaction parameters of the zeolite atoms used in this study are $\sigma_{\mathrm{O}}=2.545 \AA, \sigma_{\mathrm{Na}}=3.37 \AA, \varepsilon_{\mathrm{o}}=155.1 \mathrm{~K}$, $\varepsilon_{\mathrm{Na}}=4.72 \mathrm{~K}$ (Santikary et al 1992). The cross-interaction parameters between $n$-butane and the zeolite atoms are obtained by the use of combination rules (Allen and Tildesley 1987) and are listed in table $2 \mathrm{~b}$. The dispersion and the repulsive interaction terms between the sorbate and the zeolite atom are given by $A_{\mathrm{sz}}=4 \varepsilon_{\mathrm{sz}} \sigma_{\mathrm{sz}}^{6}$ and $B_{\mathrm{sz}}=4 \varepsilon_{\mathrm{sz}} \sigma_{\mathrm{sz}}^{12}$ respectively.

The total potential energy of interaction $U_{10 t}$ is obtained from each of the above-mentioned interactions by summing over the contributions from individual molecules and their mutual interactions and interactions with the zeolite atoms. Therefore, for a system with $N$ alkane mol ules each with $M$ sites the total bond-bending interaction energy, $U_{\mathrm{b}}$, is the sum over all bond-bending interactions:

$$
U_{\mathrm{b}}=\sum_{i=1}^{N} \sum_{j=1}^{M-2} \phi_{\mathrm{b}}\left(\theta_{i j}\right)
$$

The total torsional interaction energy, $U_{t}$, is the sum over all torsional interactions: 


$$
U_{1}=\sum_{i=1}^{N} \sum_{j=1}^{M-3} \phi_{1}\left(\phi_{i j}\right)
$$

The total intramolecular non-bonded interaction energy, $U_{n \mathrm{nb}}$, is obtained by summing the interaction between the sites of the same molecule separated by more than three bonds:

$$
U_{\mathrm{nb}}=\sum_{i=1}^{N} \sum_{j=1}^{M-4} \sum_{k=j+4}^{M} \phi_{\mathrm{nb}}\left(r_{i j k}\right) .
$$

The total intermolecular interaction energy, $U_{\mathrm{ss}}$, between two different alkane molecules is the sum over all site-site interactions:

$$
U_{\mathrm{ss}}=\frac{1}{2} \sum_{i=1}^{N} \sum_{j \neq i}^{N} \sum_{k=1}^{M} \sum_{i=1}^{M} \phi_{\mathrm{ss}}\left(r_{i j k}\right)
$$

The total alkane-zeolite interaction energy, $U_{\mathrm{sz}}$, is the sum over interactions between the sites of the alkane molecules with all zeolite atoms $\left(N_{z}\right)$ :

$$
U_{\mathrm{sz}}=\sum_{i=1}^{N} \sum_{i=1}^{M} \sum_{k=1}^{N} \phi_{\mathrm{sz}}\left(r_{i j k}\right) .
$$

The total potential energy of interaction is therefore given by

$$
U_{\mathrm{tot}}=U_{\mathrm{b}}+U_{\mathrm{t}}+U_{\mathrm{nb}}+U_{\mathrm{ss}}+U_{\mathrm{sz}}
$$

Note that for $n$-butane $U_{\mathrm{nb}}=0$.

\subsection{Configurational-bias Monte Carlo (CBMC) for alkanes}

Before describing the configurational-bias Monte Carlo (CBMC) method, it would be worthwhile to discuss the usefulness and limitations of the conventional Monte Carlo (MC) technique. In a typical MC move, a particle is moved to an arbitrary position. Therefore, in a MC simulation one does not have to follow the 'natural path' of the particles. This is a significant advantage of MC simulation techniques over molecular dynamics (MD), particularly for systems where diffusion is slow, and, consequently, a very long MD run is essential to obtain reliable results. The conventional $\mathrm{MC}$ technique is an efficient method for systems consisting of small molecules, but it fails to work for complex systems such as long chain alkanes, polymers, biomolecules etc. For example, random insertions of long flexible alkanes within the highly ordered and confining environment of the intracrystalline pores of zeolites have a very low probability of success due to very high probability of overlap with the zeolitic walls. To illustrate, the probability for a successful move of a small methane molecule within a zeolite is approximately $10^{-3}$, for ethane this is of the order of $10^{-6}$, and for longer alkanes this probability is so small that 
almost none of the attempted moves will be accepted. This problem can be overcome by using biased insertions instead of random ones. A number of $\mathrm{MC}$ techniques have appeared in literature in recent years which utilize biased chain insertions (Harris and Rice 1988; Frenkel et al 1992; de Pablo et al 1992, 1993; Siepmann and Frenkel 1992; Siepmann et al 1993a). This class of simulation methods are known as 'configurational-bias Monte Carlo' or CBMC. All these techniques are based on the basic idea of Rosenbluth and Rosenbluth (1955) and involve 'growing' of alkane chains atom-by-atom instead of a random insertion, with a particular bias function that preferentially samples low-energy conformations. The bias introduced while growing a chain molecule is exactly removed by adjusting the acceptance rules (Harris and Rice 1988; Frenkel et al 1992; Siepmann and Frenkel 1992). The CBMC techniques have been found to be very efficient in simulating various systems such as $n$-alkanes (Laso et al 1992; Siepmann et al 1993a,b), phase equilibria of chain molecules (Mooij et al 1992) etc. In our work we have employed CBMC technique as proposed by Smit and Siepmann $(1994 a, b)$, which is described below.

The underlying idea of this technique is to generate trial conformations of the alkane molecules in a smart way i.e. in such a way that the trial chain avoids overlapping with itself and with other chains in the system and also takes into account the intramolecular potentials. This smart generation of conformations is an efficient way of sampling and it gives rise to high acceptance probability of the attempted moves.

Consider a system with $N$ identical alkane molecules each with $M$ sites. A new conformation of an alkane molecule is generated, using the following steps: Step 1: One alkane molecule and one of its sites are selected randomly. Step 2: The selected alkane molecule is then either completely or partially re-grown depending on the selected site. If the selected site is the first or last bead of the chain then the CBMC move involves discarding the entire molecule and then regrowing it site-by-site. If the selected site is in the interior of the chain, then a random choice is made to decide whether to re-grow the head or the tail part of the chain. Now, suppose a non-terminal site $l$ is chosen. If the tail part is selected, then the sites $l$ to $M$ are re-grown. If the head is selected, then the sites 1 to $l$ are re-grown. This move is very efficient in changing the conformation of an alkane molecule. Now, suppose a non-terminal site $l$ is chosen in a particular move and the tail part of the chain is to be re-grown. This process of re-growing a chain is shown schematically in figure 2. A set of $k$ trial positions is generated as $\{\mathbf{b}\}=\left(\mathbf{b}_{1}, \mathbf{b}_{2}\right.$, $\left.\ldots, \mathbf{b}_{\mathbf{k}}\right)$ on the surface of a sphere with $(l-1)$-th atom at the centre of the sphere and the radius equal to the bond length. This set of trial orientations is generated using the internal part of the potential (i.e. only the bond-bonding and torsional interactions), which results in the following distribution for the $l$ th atom

$$
p_{l}^{\mathrm{int}}\left(\mathbf{b}_{i}\right) \mathrm{d} \mathbf{b}_{i}=\frac{\exp \left[-\beta u_{l}^{\mathrm{n}, \mathrm{int}}\left(\mathbf{b}_{i}\right)\right]}{C} \mathrm{d \mathbf {b } _ { i }}
$$

where $\beta=1 / k_{\mathrm{b}} T$ and $C$ is a normalization constant given by

$$
C \equiv \int_{b} \exp \left[-\beta u_{i}^{\mathrm{n} . \mathrm{int}}\left(\mathbf{b}_{i}\right)\right] \mathrm{d} \mathbf{b}_{i} .
$$


In CBMC scheme one does not have to calculate this constant. This internal potential energy $u_{i}^{\text {n. int }}\left(\mathbf{b}_{i}\right)$ and hence the probability $p_{i}^{\text {int }}\left(\mathbf{b}_{i}\right)$ depends on which type of atom is being inserted. Of each of these $k$ trial positions the external interaction energy $u_{j}^{\text {n.ext }}\left(\mathbf{b}_{j}\right)$ is calculated with the atoms of the other alkane molecules and with those of the zeolite and also with those sites of the molecule which are already grown and separated by at least four sites. Then one of these $k$ trial positions is selected with a probability

$$
p_{l}^{\text {ext }}\left(\mathbf{b}_{j}\right)=\frac{\exp \left[-\beta u_{l}^{\mathrm{n} \cdot \mathrm{ext}}\left(\mathbf{b}_{j}\right)\right]}{w^{\mathrm{n} \cdot \operatorname{ext}}(l)},
$$

where

$$
w^{\text {n.ext }}(l)=\sum_{j=1}^{k} \exp \left[-\beta u_{,}^{\mathrm{n} \cdot \mathrm{ext}}\left(\mathbf{b}_{j}\right)\right]
$$

This process is repeated until the last site of the chain is reached. When regrowing of the entire alkane chain of length $M$ is complete, one calculates

$$
W^{\mathrm{n}}=\prod_{i=1}^{1-1} \exp \left[-\beta u^{\mathrm{n}, \mathrm{ext}}(i)\right] \prod_{j=1}^{M} w^{\mathrm{n} \text { ext }}(j) .
$$

Step 3: After a new conformation of the selected chain has been generated, one proceeds by considering the old configuration of the selected molecule. The external energy $u^{0 . \text { ext }}(l)$ is calculated and a set of $(k-1)$ trial orientations is generated. One then calculates,

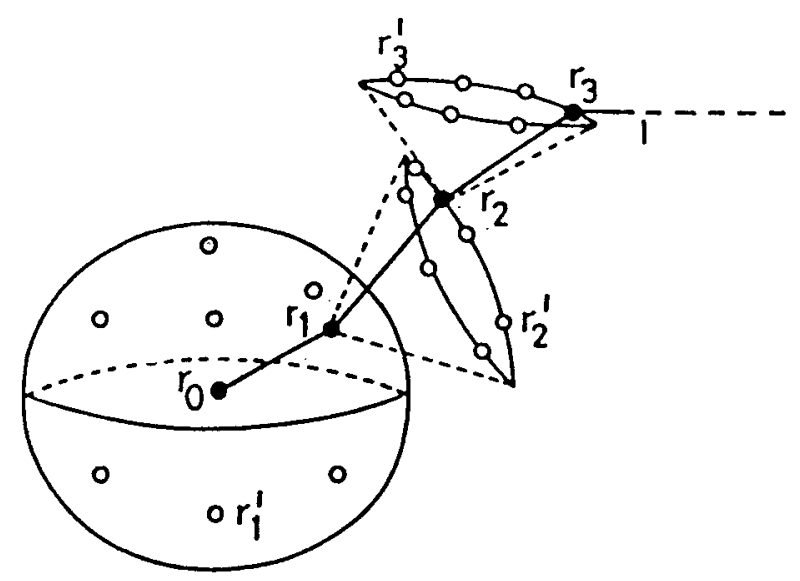

Figure 2. Schematic representation of the CBMC move to efficiently grow conformations of alkanes confined in zeolitic pores. $r_{0}$ is the starting position of the chain. $r_{1}, r_{2}$ etc (shown as filled spheres) are the additional atomic positions, which are selected from among a set of trial positions $r_{i}^{\prime}$ generated on the surface of a sphere with radius equal to the bond length (shown as empty spheres). 


$$
w^{(0, \operatorname{ext}}(l)=\exp \left[-\beta u^{0, \operatorname{ext}}(l)\right]+\sum_{j=2}^{k} \exp \left[-\beta u^{0, \operatorname{ext}^{2}}\left(\mathbf{b}_{j}\right)\right] .
$$

When all the sites of the molecule have been considered, one calculates for the entire molecule

$$
W^{o}=\prod_{i=1}^{1-1} \exp \left[-\beta u^{\mathrm{o}, \mathrm{ext}}(i)\right] \prod_{j=1}^{M} w^{0, \mathrm{ext}}(j) .
$$

Step 4: Finally, whether the new conformation of the alkane molecule will be accepted or not is decided by the acceptance rule

$$
\operatorname{acc}(o \rightarrow n)=\min \left(1, W^{n} / W^{o}\right)
$$

This acceptance rule removes the bias of the growing process, obeys detailed balance, and hence the conformations are generated with the correct Boltzmann weight.

\subsection{Computational details}

2.4a Canonical ensemble Monte Carlo method for clusters: In this study, we have used the Metropolis algorithm (Metropolis et al 1953) to carry out Monte Carlo simulations of argon clusters confined to cavities in zeolites. We have also studied the melting behaviour of an $\mathrm{Ar}_{13}$ cluster confined in zeolite $\mathrm{L}$.

The $\mathrm{MC}$ simulations in zeolite $\mathrm{NaCaA}$ were carried out with a simulation cell that consisted of a single unit cell of the zeolite. For studies of $\operatorname{Ar}_{13}$ confined in zeolite L, the simulation cell was made up of $2 \times 2 \times 3$ unit cells. In all cases, the zeolite framework was assumed to be rigid and merely provided an external field.

Every Monte Carlo step consisted of an attempt to displace each cluster atom in turn. Whenever an attempt was such that the distance of the cluster atom from the cluster centre-of-mass (COM) was greater than $4 \sigma$, such a move was rejected. Periodic boundary conditions were imposed and the nearest image used in the calculation of both cluster atom-cluster atom, as well as cluster atom-zeolite lattice interactions. A spherical cutoff of $10 \AA$ was used for both guest-guest and guestzeolite interactions.

At each temperature, the system was equilibrated for $10^{6} \mathrm{MC}$ steps. This was followed by a production run of $7 \times 10^{6} \mathrm{MC}$ steps. Coordinates of the cluster atoms and the associated energies of interaction were stored every $100 \mathrm{MC}$ steps from which all properties were calculated. The configuration of the cluster at the first step after the equilibration run at a given temperature was used as the starting configuration for the $\mathrm{MC}$ run at the next higher temperature.

2.4b Configurational-bias Monte Carlo for n-alkanes: Monte Carlo (MC) calculations have been carried out in the canonical ensemble at fixed $(\mathrm{N}, \mathrm{V}, \mathrm{T})$. Cubic periodic boundary conditions were employed. An attempt is made to displace a molecule randomly, rotate it by a random magnitude around a randomly chosen 
axis and, finally, to re-grow either a part or whole of it. $\mathrm{N}$ such attempts comprise a MC cycle during which the molecule itself is selected randomly. CBMC method has been employed to re-grow the molecules. Attempt to re-grow the molecules is carried out as proposed by Smit and Siepmann (1994a) and the method is referred to as configurational-bias Monte Carlo (CBMC). The centre-of-mass of the selected molecule is displaced randomly within $\pm 0.3 \AA$ and a maximum rotation of the molecule by $\pm 3^{\circ}$ is allowed around a randomly chosen axis. During the CBMC move, the number of trial positions, $k$, generated for each site using the internal part of the potential is 6 . One unit cell of zeolites $\mathrm{NaY}$ and $\mathrm{NaCaA}$, each consisting of eight $\alpha$-cages have been employed in the present study. All the simulations have been carried out at a fixed temperature of $400 \mathrm{~K}$ with eight $n$-alkane molecules, corresponding to a sorbate concentration, $c$, of one $n$-alkane molecule per $\alpha$-cage. At the start of the simulation, there was precisely one n-alkane molecule in each of the eight $\alpha$-cages. For every run, equilibration was carried out over $2500 \mathrm{MC}$ cycles. This is followed by production runs of $10^{5} \mathrm{MC}$ cycles to obtain averages of the properties. A spherical cut-off of $12 \AA$ has been employed in evaluating both sorbate-sorbate and sorbate-zeolite interaction energies.

\section{Results and discussion}

\subsection{Argon clusters in zeolites}

3.1a Structure and energy: Clusters of rare gases have been widely investigated in their free state, viz. when they are not confined in any medium (Etters and Kaelberer 1977; Nauchitel and Pertsin 1980; Quirke and Sheng 1984; Honeycutt and Andersen 1987; Berry and Cheng 1992; Berry 1994). Before we discuss the properties of clusters confined in zeolites, it may be worthwhile to briefly recollect the properties of free clusters of rare gases. Free rare-gas clusters exhibit interesting structural, energetic and dynamical properties. Clusters of 4-55 atoms assume structures with high symmetry. Thus, for example, a cluster with 4 atoms prefers a tetrahedral, 5 a trigonal bipyramidal, 6 an octahedral, 7 a pentagonal bipyramidal, 13 an icosahedral geometry (see figure 3). It is not uncommon to find clusters confined in host matrices. It is of considerable importance to know how and in what way the behaviour of such clusters would be altered by the confinement. In particular, we would like to address the structural and energetic aspects of confined clusters vis-a-vis those of free clusters.

Interaction energies, $U_{\mathrm{p}}$, for free $\mathrm{Ar}_{n}$ clusters, for $n=4,19$ are listed in table 3. In figure 4 , we have plotted the difference in the total interaction energies of free Ar clusters:

$$
\Delta U=U_{n}-U_{n-1}
$$

where $U_{n}=U \cdot n / \varepsilon$ is the total interaction energy for a cluster of size $n$ in dimensionless units. Here $U$ is the total interaction energy per particle of (4) in $\mathrm{kJ} / \mathrm{mol}$. It is seen that the curve peaks at certain values of $n$, indicating that clusters of these sizes are much stabler (see figure 4). In particular, clusters with $n=7$, 13 and 19 exhibit pronounced peaks, indicating considerable stability as compared to others. These are the magic number sizes for free argon clusters. 


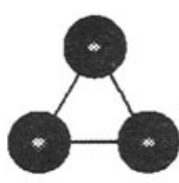

$n=3$

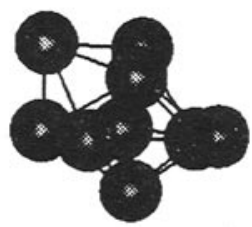

$n=9$

\section{Preferred geometries of free $\mathrm{Ar}_{n}$ clusters}

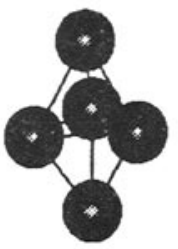

$n=5$

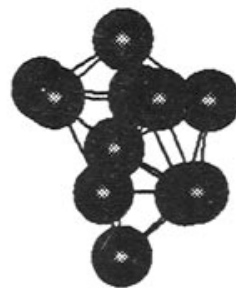

$n=11$

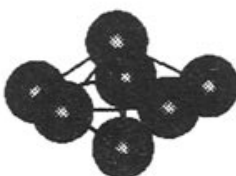

$n=7$

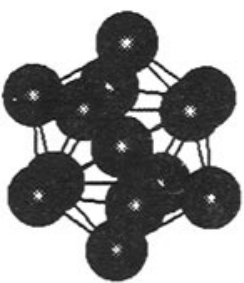

$n=13$

ligure 3. The preferred geonetries of some free $\operatorname{Ar}$ clusters are shown with $4<n<19$.

Table 3. The minimum energy configurations obtained for $\mathrm{Ar}_{n}, n=4-19$ by the process of slow heating have been listed. The temperature at which this minimum energy was observed has been indicated as well as temperature at which the cluster splits.

\begin{tabular}{|c|c|c|c|c|c|c|c|c|c|}
\hline \multirow[b]{2}{*}{$\begin{array}{l}\text { Cluster } \\
\text { size }\end{array}$} & \multirow[b]{2}{*}{$U_{\mathrm{r}}(\varepsilon)$} & \multicolumn{3}{|c|}{ Starting configuration } & \multicolumn{3}{|c|}{ Minimum energy configuration } & \multirow[b]{2}{*}{$\begin{array}{c}T_{1} \\
(\mathrm{~K})\end{array}$} & \multirow[b]{2}{*}{$\begin{array}{r}T_{2} \\
(\mathrm{~K})\end{array}$} \\
\hline & & $\begin{array}{c}U_{\mathrm{gu}} \\
(\mathrm{kJ} / \mathrm{mol})\end{array}$ & $\underset{(\mathrm{kJ} / \mathrm{mol})}{U_{\mathrm{gh}}}$ & $\begin{array}{c}U \\
(\mathrm{~kJ} / \mathrm{mol})\end{array}$ & $\begin{array}{c}U_{\mathrm{gg}} \\
(\mathrm{kJ} / \mathrm{mol})\end{array}$ & $\underset{(\mathrm{kJ} / \mathrm{mol})}{U_{\mathrm{gh}}}$ & $\begin{array}{c}U \\
(\mathrm{~kJ} / \mathrm{mol})\end{array}$ & & \\
\hline 4 & $6 \cdot 0$ & -0.5059 & -1.2623 & +0.7563 & -17.8414 & -1.0083 & -16.8332 & 7 & 52 \\
\hline 5 & $9 \cdot 104$ & -11.2586 & -1.6916 & -9.5670 & -17.7544 & -0.8571 & -16.8973 & 7 & 54 \\
\hline 6 & 12.712 & $-4 \cdot 4340$ & -1.7296 & $-2 \cdot 7044$ & $-18 \cdot 1467$ & -1.5466 & $-16 \cdot 6002$ & 47 & 55 \\
\hline 7 & $16 \cdot 505$ & $-9 \cdot 6940$ & $-2 \cdot 3179$ & $-7 \cdot 3761$ & -18.4552 & -1.8057 & $-16 \cdot 6495$ & 26 & 70 \\
\hline 8 & 19.822 & $+27 \cdot 1676$ & -1.5252 & +28.9300 & -18.2527 & -1.7175 & -16.5352 & 53 & 56 \\
\hline 9 & $24 \cdot 113$ & -9.0494 & $-2 \cdot 1082$ & -7.0313 & -18.3671 & -1.8806 & -16.4865 & 49 & 62 \\
\hline 10 & $28 \cdot 420$ & +0.9451 & -1.7636 & $+2 \cdot 7088$ & -17.9856 & -1.8537 & -16.1319 & 40 & 59 \\
\hline 11 & 32.765 & +28.2497 & -1.5216 & +29.7714 & -18.0676 & $-2 \cdot 1053$ & -15.9623 & 6 & 50 \\
\hline 12 & 37.967 & -9.2615 & $-3 \cdot 1403$ & $-6 \cdot 1212$ & -17.9876 & -2.0139 & -15.9737 & 58 & 60 \\
\hline 13 & $44 \cdot 327$ & +10.7191 & $-3 \cdot 3911$ & +14.1102 & -17.9057 & -2.2551 & -15.6507 & 67 & 68 \\
\hline 14 & 47.845 & +17.4699 & $-J \cdot 1480$ & +18.6179 & -18.3353 & -2.3279 & -16.0074 & 63 & 64 \\
\hline 15 & 52.323 & $-4 \cdot 1057$ & -1.4572 & -2.6485 & -18.3294 & -2.5558 & -15.7737 & 6 & 75 \\
\hline 16 & 56.816 & $-4 \cdot 1249$ & -1.5721 & -2.5528 & -18.0851 & -3.2009 & -14.8841 & 46 & 61 \\
\hline 17 & $61 \cdot 318$ & +10.7135 & -1.6462 & $+12 \cdot 3596$ & -18.1718 & -3.1942 & -14.9776 & 7 & 67 \\
\hline 18 & 66.531 & +25.0924 & -0.7178 & +25.8102 & -18.5599 & -2.9552 & -15.6047 & 6 & 78 \\
\hline 19 & 72.660 & +6.0538 & -1.4230 & +7.4767 & -18.4711 & -3.5066 & -14.9645 & 6 & 86 \\
\hline
\end{tabular}

$T_{1}$ : Temperature at which minimum crigy configuration is observed; $T_{2}$ : temperature at which the cluster splits. 


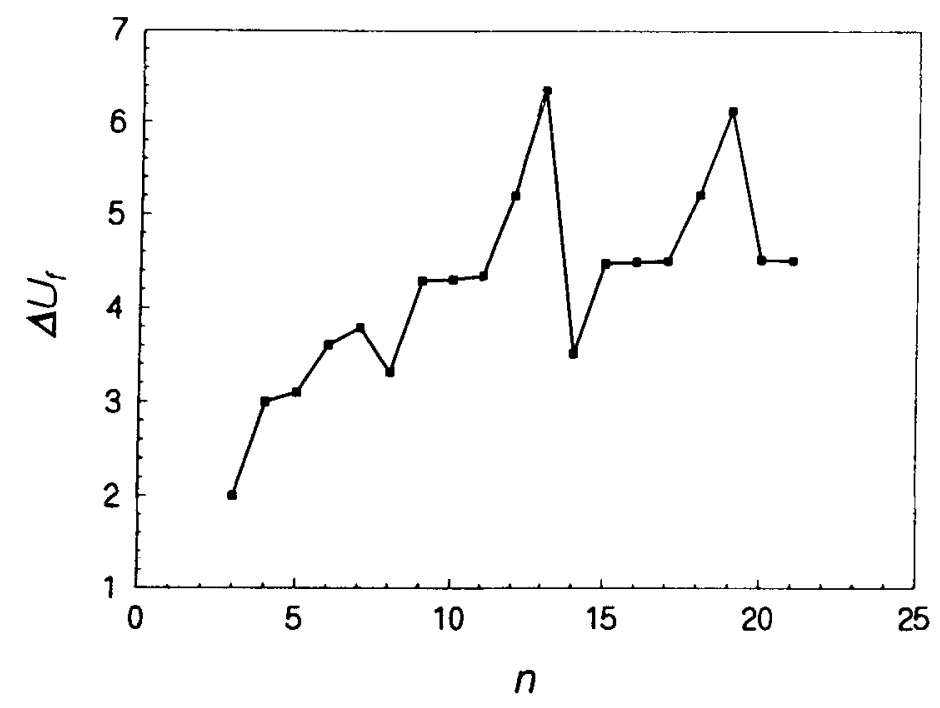

Figure 4. The differences in the binding energies are shown as a function of cluster size for free $\mathrm{Ar}$ clusters. The peaks in the curve correspond to the so-called magic number cluster sizes: 7,13 and 19

There have been a few studies on rare-gas clusters confined in host matrices ( $\mathrm{Li}$ and Berry 1995a, b). It is not clear from these whether magic number clusters exist among rare-gas clusters confined in zeolites or other host matrices. We have carried out a detailed calculation in which we have studied the structure and the energies associated with $\mathrm{Ar}_{n}$ clusters confined in the $\alpha$-cages of the host matrix, zeolite $\mathrm{NaCaA}$, for $n$ varying between 4 and 19. Specifically, the clusters were present in the $\alpha$-cages of zeolite $\mathrm{NaCaA}$. In order to obtain the structure corresponding to the lowest energy minimum, we tried to locate the minimum in the total energy comprising the argon-argon and argon-zeolite interaction energies. This was attempted by carrying out Monte Carlo runs at temperatures starting from $5 \mathrm{~K}$ up to the temperature at which the cluster splits in steps of $1 \mathrm{~K}$. This slow heating of the cluster was performed, starting from an arbitrary configuration of the cluster. At low temperatures, the cluster atoms are not very mobile. However, around the melting temperature, we expect that the cluster atoms will be able to sample much more of phase space - they will perhaps be able to overcome barriers that separate local minima from the global minimum. And so, the global minimum is likely to be sampled when the temperature is high enough for the cluster atoms to sample phase space efficiently, but low enough for the cluster to remain a single integrated unit (i.e. without splitting up into smaller sub-clusters) provided that sufficient time is available for the cluster to sample all of the phase space accessible to it at that temperature. For this purpose we have carried out the simulation for a duration of $5000 \mathrm{MC}$ steps at every temperature. To ensure that we have found low-enough energy minima, the procedure is repeated starting from two different initial configurations. The minimum energy is taken to be the lowest of all energies over all $\mathrm{MC}$ steps and all temperatures.

Normally, global optimization is performed using the method of simulated annealing 
(Kirkpatrick et al 1983) where the system temperature is brought down sufficiently slowly. The method employed by us here does exactly the opposite: the temperature is slowly increased until the system samples the configuration space effectively and manages to reach the minimum.

Table 3 lists the energy of the starting configuration, the lowest energy obtained, the temperature at which minimum energy was located and the temperature at which the cluster splits. The individual contributions of the guest-guest and the guest-host interactions have also been listed. It is evident from table 3 that different starting configurations lead to energies which differ at most by $3.6 \%$ of each other. Figure 5 shows a plot of $\Delta U_{n}, \Delta U_{n, g g}$, as well as $\Delta U_{n \text {,gh }}$ as a function of $n$. As the predominant term is the guest-host interaction term, the behaviour of $\Delta U_{n}$ and $\Delta U_{n, g h}$ are similar. The curve peaks at several values of $n$. In particular, $n=14$ and 18 show pronounced peaks, suggesting the possible existence of magic numbers in argon clusters confined in zeolite $\mathrm{NaCaA}$. However, it is necessary to obtain other properties of these clusters, such as the melting behaviour, before it can be said unambiguously that these cluster sizes are magic numbers for confined clusters in zeolite $\mathrm{NaCaA}$. Also, it is important that a more exhaustive search for the minimum energy is carried out. The structures corresponding to the minimum energies for confined clusters of various sizes (listed in table 3) are displayed in figure 6 . The precise geometry of the cluster would depend on the symmetry of the confining medium and the interactions between the medium and the guest. The minimum energy structures for the clusters would be determined by the combination of the guest-guest and the guest-host potential energy surface, and is, therefore, more complex and is not predicted easily. There often exists more than one structure with little difference in energies.

3.1b Instantaneous normal mode spectra for rare-gas clusters: Instantaneous normal mode (INM) analysis was originally proposed by Seeley and Keyes (1989) for liquids in order to obtain dynamical properties from a series of configurations obtained either from Monte Carlo or from molecular dynamics simulations and from any ensemble. Normally, one would have to obtain dynamical quantities of interest from simulations that have been carried out in the micro-canonical (NVE) ensemble, using molecular dynamics. Subsequently, Adams and coworkers (1990a) employed INM to study properties of free rare-gas clusters during the process of melting. Attempts to obtain values of diffusion coefficients and other dynamical properties from INM have met with limited success (Adams and Stratt 1990b, c; Beck and Marchioro 1990). There are, however, certain insights that could be gained from INM by the calculation of quantities such as the percentage of imaginary frequencies. Monte Carlo simulations indicate that a free $\mathrm{Ar}_{13}$ cluster when heated exhibits a rigid-nonrigid transition from a solid-like to a liquid-like transition around $26 \mathrm{~K}$. We refer to this as the melting temperature. $\delta$, the average mean squared pair distance fluctuation, is defined as

$$
\delta=\frac{2}{N(N-1)} \sum_{i<j} \frac{\left(\left\langle r_{i j}^{2}\right\rangle-\left\langle r_{i j}\right\rangle^{2}\right)^{1 / 2}}{\left\langle r_{i j}\right\rangle},
$$

here $r_{i j}$ are the distances between any two cluster atoms and \langle\rangle implies averaging 
Clusters in confined regions...

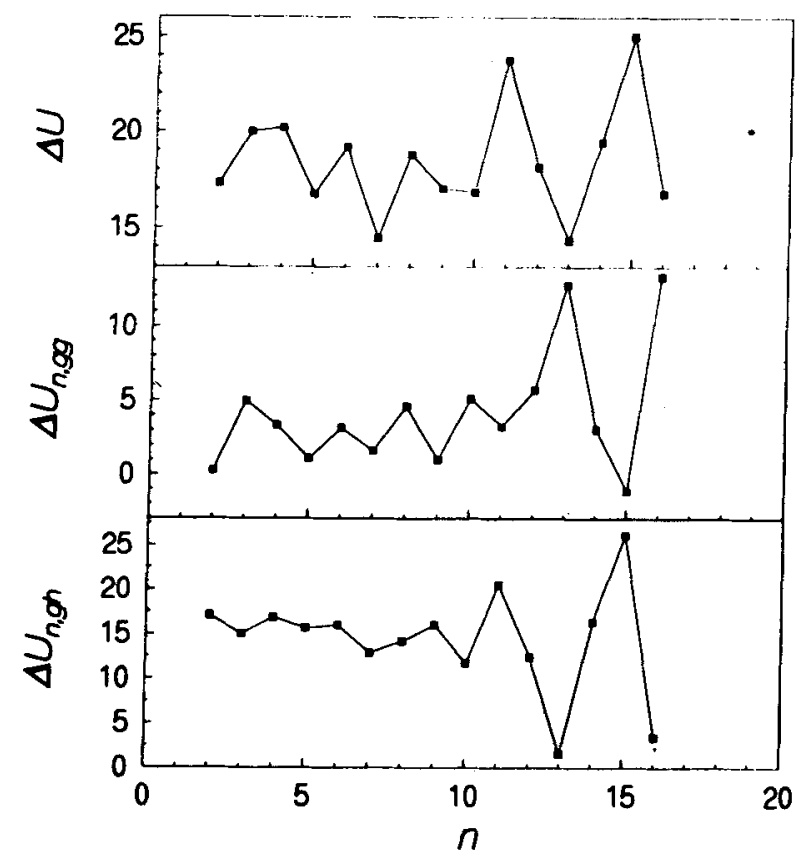

ligure 5. The differences in the binding energies are hown as a function of cluster size for $\mathrm{Ar}_{n}$ clusters confined to the $a$-cages in zolite NaCaA.

\section{Preferred geometries of $\mathrm{Ar}_{n}$ clusters in $\mathrm{NaCaA}$}

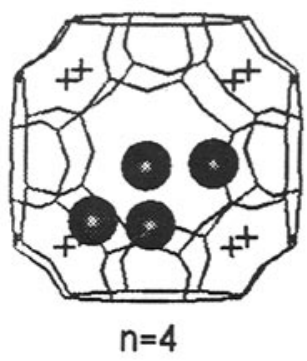

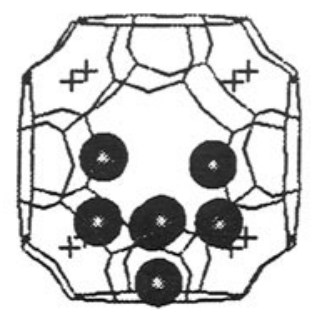

$n=7$

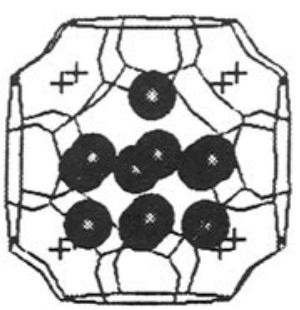

$n=11$

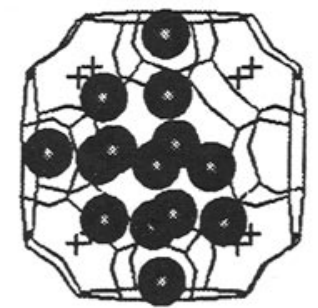

$n=14$

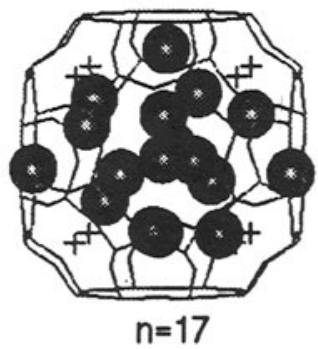

Figure 6. The preferred geometries of some $\mathrm{Ar}_{n}$ clusters confined in geolite NaCad are shown, where $4<n<19$. 
over the entire run. This quantity is usually used to monitor the melting of clusters. The behaviour of $\delta$ with temperature for a free $\operatorname{Ar}_{13}$ cluster is shown in figure 7. INM spectra were calculated using about $200 \mathrm{MC}$ configurations at different temperatures. Figure 8 shows the INM spectra for the free $\operatorname{Ar}_{13}$ cluster at various temperatures. Here the imaginary frequencies are plotted on the negative $\mathrm{x}$-axis. At every temperature two peaks are observed in the spectra, one at a real frequency and another at an imaginary frequency. At low enough temperatures, a high-frequency peak is observed near $60 \mathrm{~cm}^{-1}$, which is characteristic of solid or bulk argon. Thus, in some sense, the central atom of the icosahedral cluster is in a bulk-like environment at low temperatures where it is completely surrounded by the other twelve argon atoms. With increase in temperature, the peak at $60 \mathrm{~cm}^{-1}$ disappears as the atoms acquire higher mobility. Also, the area under the imaginary peak increases with temperature, indicating, thereby, that at higher temperatures, the cluster atoms spend more time at the saddle points of the potential energy surface. Thus, the percentage of imaginary frequencies could be a good indicator of the mobility of the cluster atoms. We therefore plot the percentage of imaginary frequencies as a function of temperature in figure 9 . The percentage increases with temperature, but exhibits no sharp change at the melting temperature.

We shall now look at the melting behaviour of rare-gas clusters when they are confined in the cages and cavities of zeolites. Table 4 shows the variation of guest-guest, guest-zeolite and the total interaction energies with temperature for the $\mathrm{Ar}_{13}$ cluster confined in zeolite $\mathrm{NaCaA}$. Figure 10 shows the variation of $\delta$ with temperature for $\mathrm{Ar}_{13}$ cluster confined in the cavities of zeolite $\mathrm{NaCaA}$. The starting configuration had an energy of $-18.011 \mathrm{~kJ} / \mathrm{mol}$. This energy seems to be the minimum energy for an $\mathrm{Ar}_{13}$ cluster confined in an $\alpha$-calge of zeolite $\mathrm{NaCaA}$.

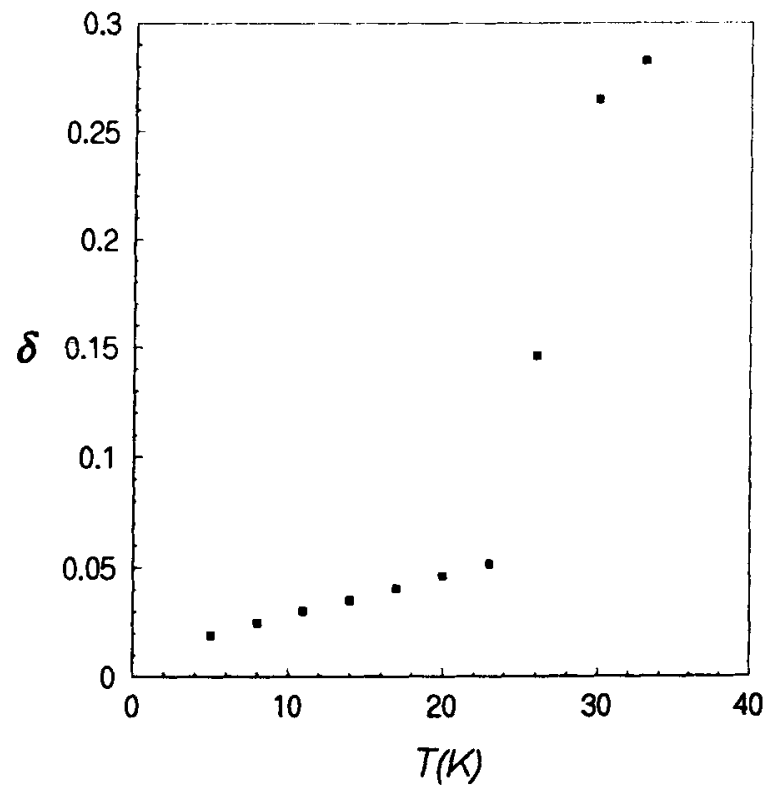

Figure 7. A plot of the root mean squared pair distance fluctuations, $\delta$, has been shown as a function of temperature for a free $\mathrm{Ar}_{13}$. 


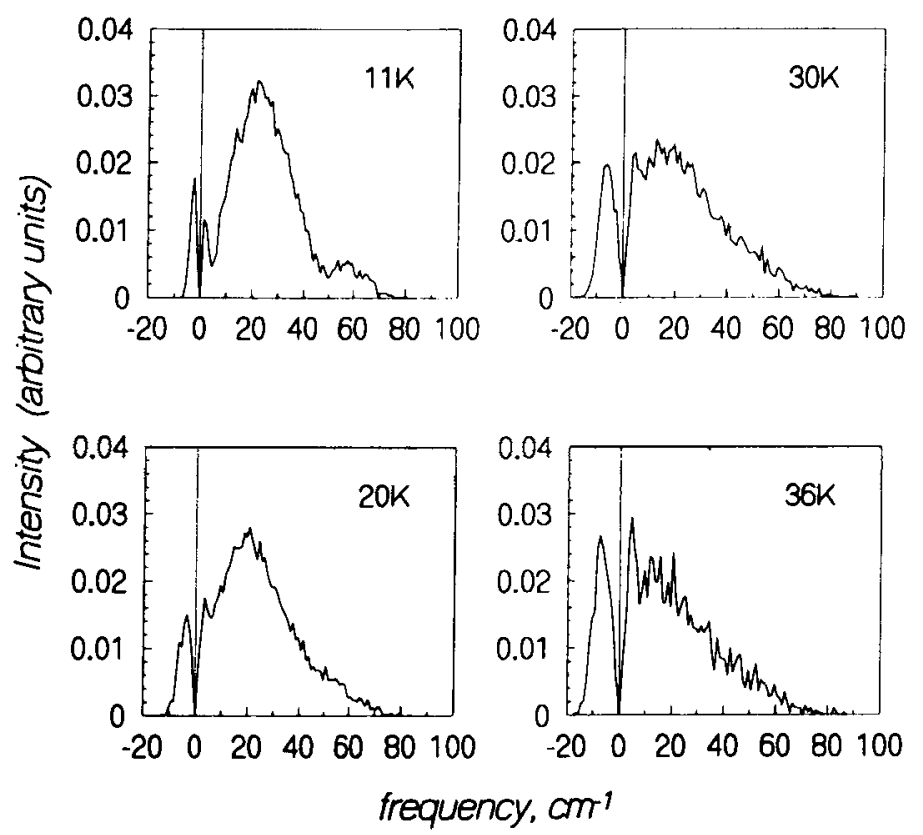

Figure 8. The instantaneous normal mode (INM) pectra are shown for a free $\mathrm{Ar}_{13}$ cluster at various temperatures.

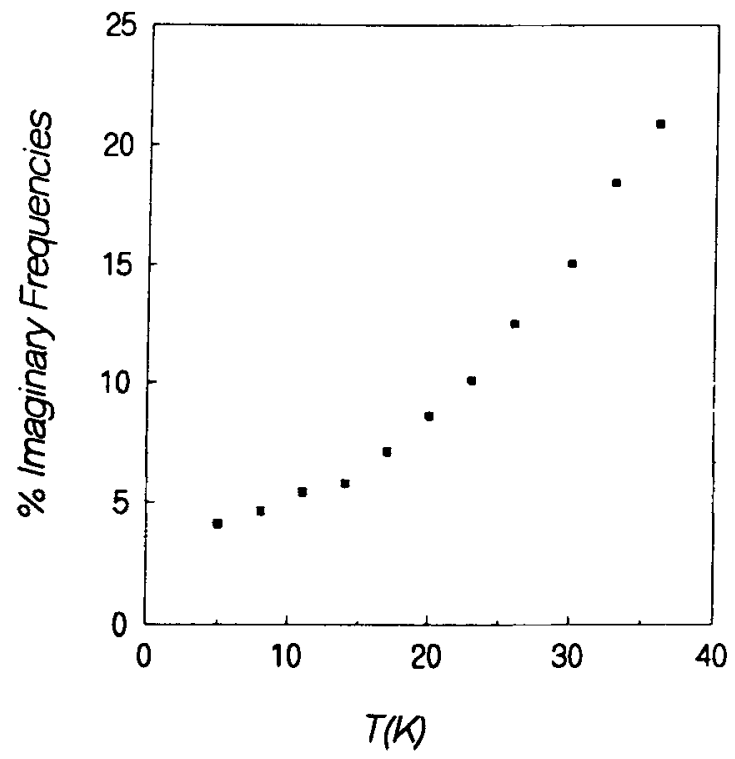

Figure 9. The percentage of imaginary frecuencies has been plotted as a function of temperature for a free $\mathrm{Ar}_{13}$ cluster. 
The melting transition does not appear to be a sharp transition as seen from the figure. The INM spectra were calculated at various temperatures and these are shown in figure 11. The INM spectra were calculated from $1400 \mathrm{MC}$ configurations by selecting every fifth configuration from $7000 \mathrm{MC}$ steps. Again, it is seen that like in the free cluster, there are two peaks at every temperature, one at an imaginary frequency and another at a real frequency. Further, it is seen that the peak at the imaginary frequency increases in intensity with temperature. This suggests that the cluster atoms spend increasing amounts of time at the saddle points of the potential energy surface. Figure 12 shows the dependence of the percentage of imaginary frequencies on the temperature. The variation is similar to the variation of $\delta$ with temperature (see figure 10): no sudden transition is found. A few differences with the results for the free cluster are noteworthy: the guest-zeolite interaction energy essentially dominates the properties of the cluster; the percentage of imaginary frequencies at any temperature for the free cluster is usually lower than that for the confined cluster. This suggests that the confined cluster spends a larger fraction of time on the saddle points in the potential energy surface as compared to the free cluster.

Earlier work on $\mathrm{Ar}_{13}$ cluster in the zeolite $\mathrm{L}$ has shown that such a cluster will exhibit the phenomenon of inverse surface melting: the inner atoms of the confined $\mathrm{Ar}_{13}$ cluster melt (acquire mobility) even before the outer atoms melt (Chitra and Yashonath 1997). This is in contrast to the surface melting behaviour exhibited by free clusters of medium to large size, where atoms on the outer surface usually melt before the inner core acquires mobility (Cheng and Berry 1992; Kunz and Berry 1993). INM spectra of the $\mathrm{Ar}_{13}$ cluster confined in zeolite $\mathrm{L}$ are shown in figure 13 for various temperatures. Each spectrum has been obtained by averaging over about $200 \mathrm{MC}$ configurations. Figure 14 shows the INM spectra for a free $\mathrm{Ar}_{13}$ cluster and also for an $\mathrm{Ar}_{13}$ cluster confined in zeolite $\mathrm{L}$ for a temperature of $5 \mathrm{~K}$. Figure 15 shows the variation of the percentage of imaginary frequencies and the total interaction energy with temperature. It is seen that they both exhibit a similar variation. The changes in the percentage of imaginary frequencies and $U$ are seen to be maximum near the melting temperature, which is $\approx 20 \mathrm{~K}$ when the

Table 4. Guest-guest and guest-zeolite interaction energies at various temperatures for $\mathrm{Ar}_{13}$ confined in zeolite $\mathrm{NaCaA}$

\begin{tabular}{|c|c|c|}
\hline$T(\mathrm{~K})$ & $\left\langle U_{\mathrm{gk}}\right\rangle(\mathrm{kJ} / \mathrm{mol})$ & $\left\langle U_{\mathrm{gh}}\right\rangle(\mathrm{kJ} / \mathrm{mol})$ \\
\hline $5 \cdot 0$ & $-2 \cdot 28938$ & -15.8354 \\
\hline 8.0 & $-2 \cdot 28004$ & -15.8075 \\
\hline 11.0 & $-2 \cdot 27063$ & -15.7794 \\
\hline 14.0 & $-2 \cdot 26117$ & -15.7514 \\
\hline 17.0 & $-2 \cdot 25157$ & $-15 \cdot 7240$ \\
\hline 20.0 & $-2 \cdot 24162$ & -15.6965 \\
\hline 23.0 & -2.23193 & -15.6692 \\
\hline $26 \cdot 0$ & -2.22156 & -15.6420 \\
\hline $29 \cdot 0$ & -2.21137 & -15.6141 \\
\hline 32.0 & $-2 \cdot 20084$ & -15.5869 \\
\hline 350 & $-2 \cdot 19043$ & -15.5597 \\
\hline 38.0 & $-2 \cdot 17948$ & -15.5324 \\
\hline
\end{tabular}




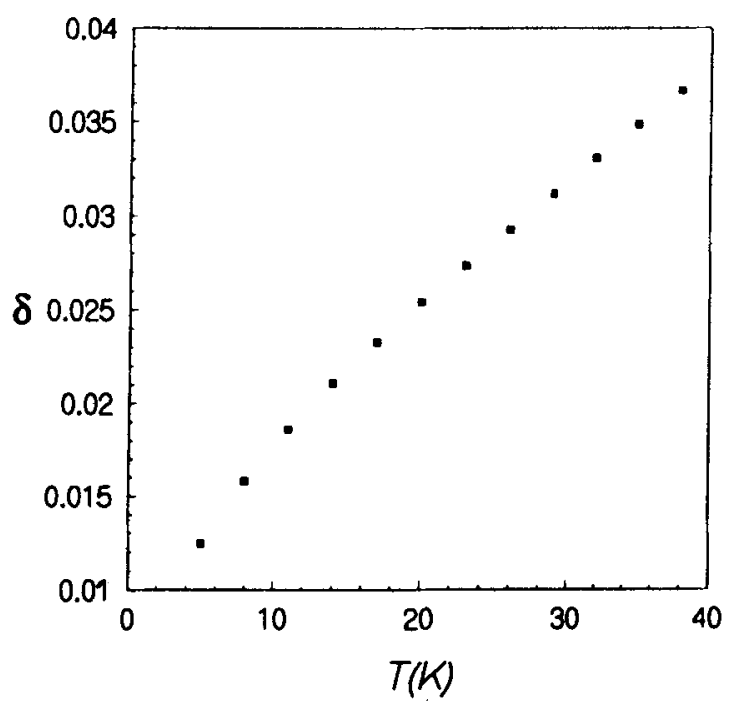

Figure 10. The root mean squared pair distance fluctuation, $\delta$, has been plotted at various temperatures for an $\mathrm{Ar}_{13}$ cluster confined in zeolite $\mathrm{NaCaA}$.

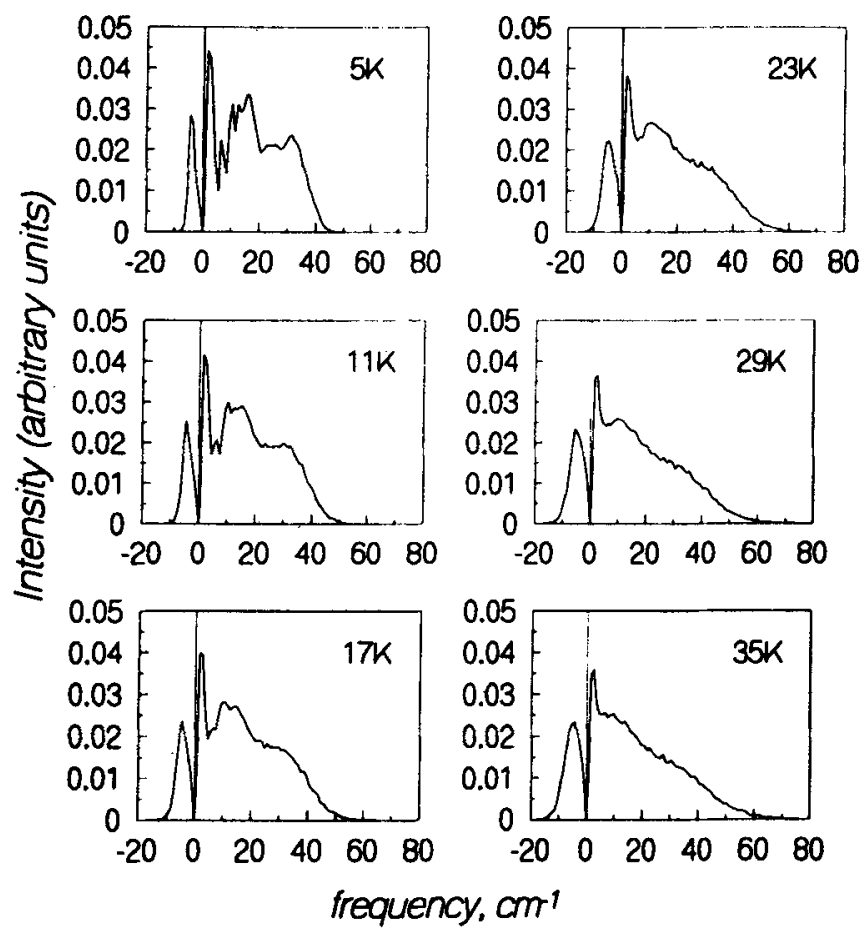

Figure 11. The instantaneous normal mode (INM) spectra are shown at different temperatures for an $\mathrm{Ar}_{13}$ cluster confined in zeolite $\mathrm{NaCaA}$. 


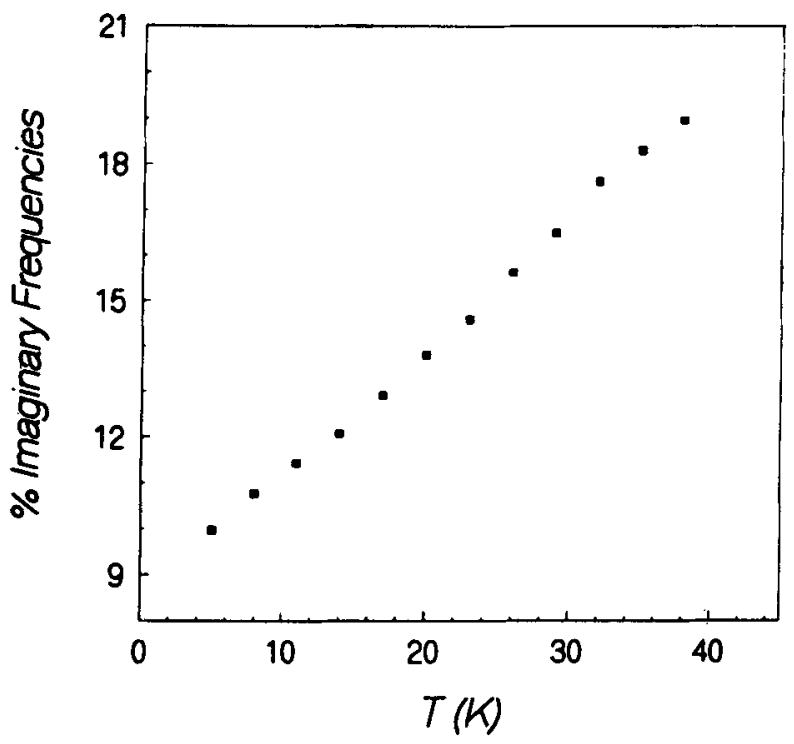

Figure 12. The percentage of imaginary frequencies has been plotted at various temperatures for an $\mathrm{Ar}_{13}$ confined in zeolite $\mathrm{NaCaA}$.

inner rare-gas atoms exhibit increased mobility. This is evident from figure 16 which shows the trajectories of each of the 13 argon atoms.

\section{$3.2 n$-Alkanes in zeolites}

3.2a Thermodynamic properties: The average values of different interaction energies, such as, $U_{\mathrm{ss}}, U_{\mathrm{sz}}, U_{\mathrm{nb}}, U_{\mathrm{b}}, U_{\mathrm{t}}$ and $U_{\mathrm{tat}}$ as well as the isosteric heats of adsorption $\left(q_{\mathrm{st}}\right)$ for different $n$-alkanes $\left(\mathrm{C}_{4} \mathrm{H}_{10}\right.$ to $\left.\mathrm{C}_{10} \mathrm{H}_{22}\right)$ adsorbed in zeolites $\mathrm{NaY}$ and $\mathrm{NaCaA}$ are listed in tables 5 and 6 , respectively. From the tables it is clear that irrespective of the chain length, $M$, of the molecules, the alkane-zeolite or sorbate-zeolite interaction energy $\left(U_{s z}\right)$, is the predominant one. Contributions from bond-bending interactions $\left(U_{\mathrm{b}}\right)$ and torsional interactions $\left(U_{\mathrm{t}}\right)$ are almost constant and rather small. The increase in alkane-zeolite or sorbate-zeolite interaction energy $\left(U_{\mathrm{sz}}\right)$ with increase in chain length is more significant in zeolite $\mathrm{NaCaA}$.

3.2b n-Alkane conformation: Figures 17 and 18 display distribution of the dihedral angles, $f(\phi)$, for $n$-alkanes, ranging from $n$-butane $\left(\mathrm{C}_{4} \mathrm{H}_{10}\right)$ to $n$-decane $\left(\mathrm{C}_{10} \mathrm{H}_{22}\right)$ confined in zeolites $\mathrm{NaY}$ and $\mathrm{NaCaA}$ respectively.

From these plots it is clear that there is no significant population of $\mathrm{C}-\mathrm{C}$ dihedral bonds in the region between trans and gauche conformations. Average relative population of trans and gauche bonds for different $n$-alkanes confined in zeolites $\mathrm{NaY}$ and $\mathrm{NaCaA}$ are listed in tables 7 and 8 , respectively.

It is clear from tables 7 and 8 that, average population of a gauche bond is higher for long alkanes $(M \geq 6)$ confined in zeolite $\mathrm{NaCaA}$, compared to that in zeolite $\mathrm{NaY}$. 


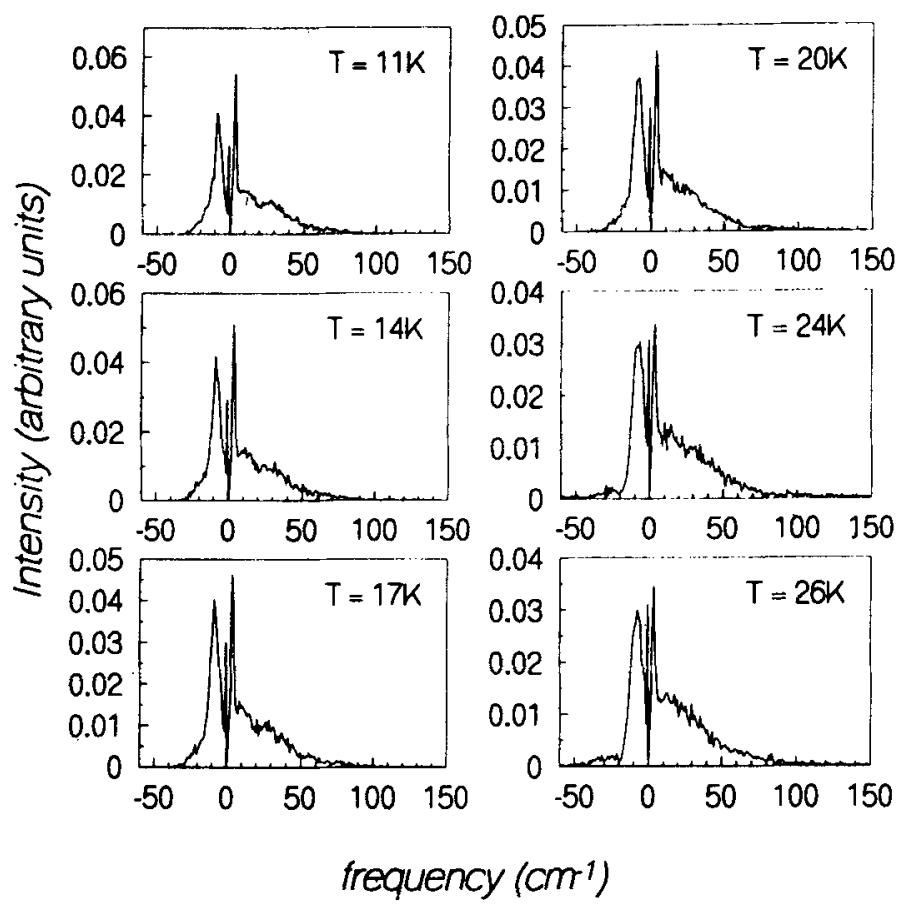

Figure 13. The instantaneous normal model (INM) spectra are shown at different temperatures for an $\mathrm{Ar}_{13}$ in zeolite $\mathrm{L}$.

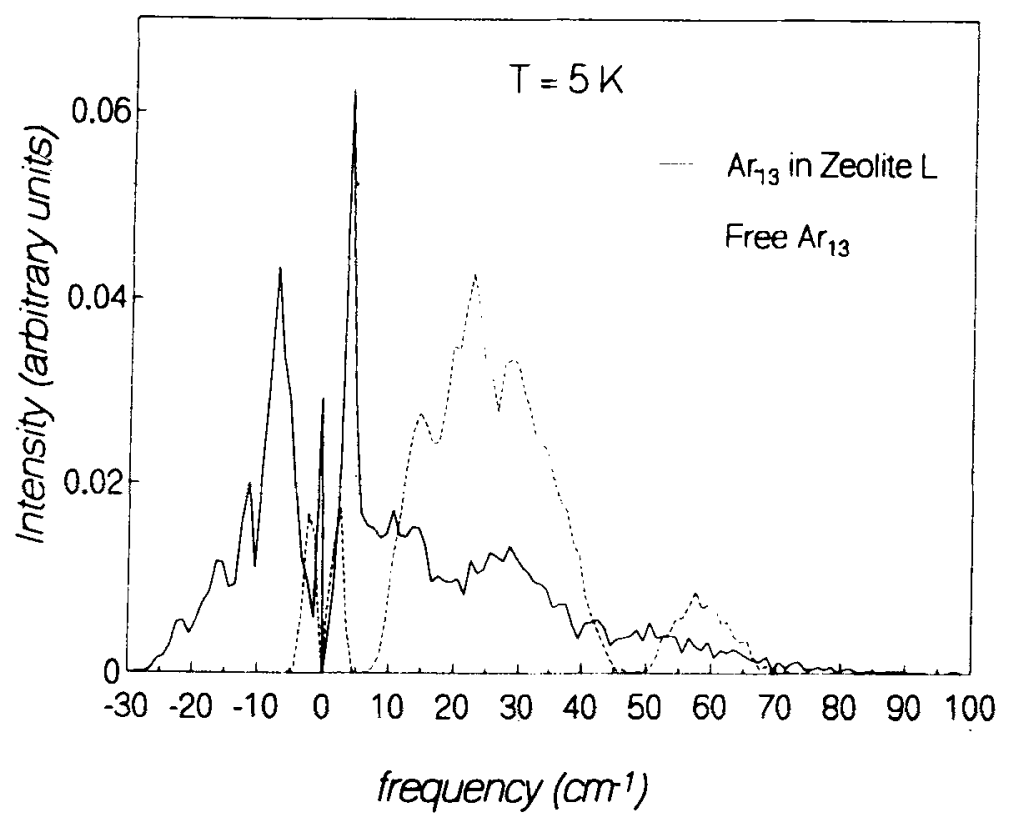

Figure 14. The instantaneous normal model (INM) spectra for a free $\operatorname{Ar}_{13}$ cluster (-- ), and an $\mathrm{Ar}_{13}$ cluster in zeolite $\mathrm{L}$ at $5 \mathrm{~K}(-)$. 
To investigate the effect of confinement on long $n$-alkanes $(M \geq 6)$ in a more detailed way, we have studied the conformation of every individual $\mathrm{C}-\mathrm{C}$ dihedral bond along the chain. Figure 19 schematically shows the convention that we have adopted in numbering the $\mathrm{C}-\mathrm{C}$ dihedral bonds.

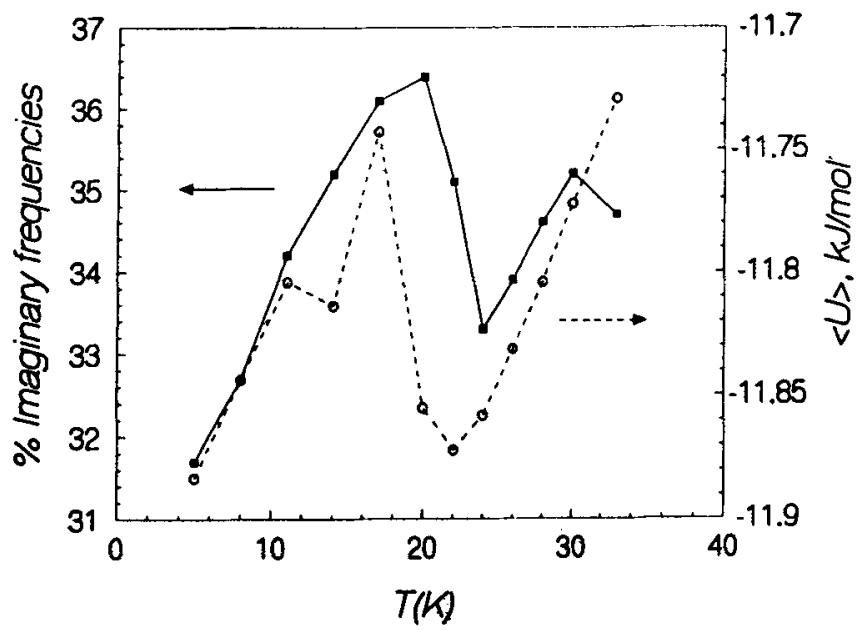

Figure 15. The variation of the total interaction energy, $U_{\text {tow }}$, as well as the percentage of imaginary frequencies will temperature is shown for an $\mathrm{Ar}_{1}$ cluster in zeolite $\mathrm{L}$.

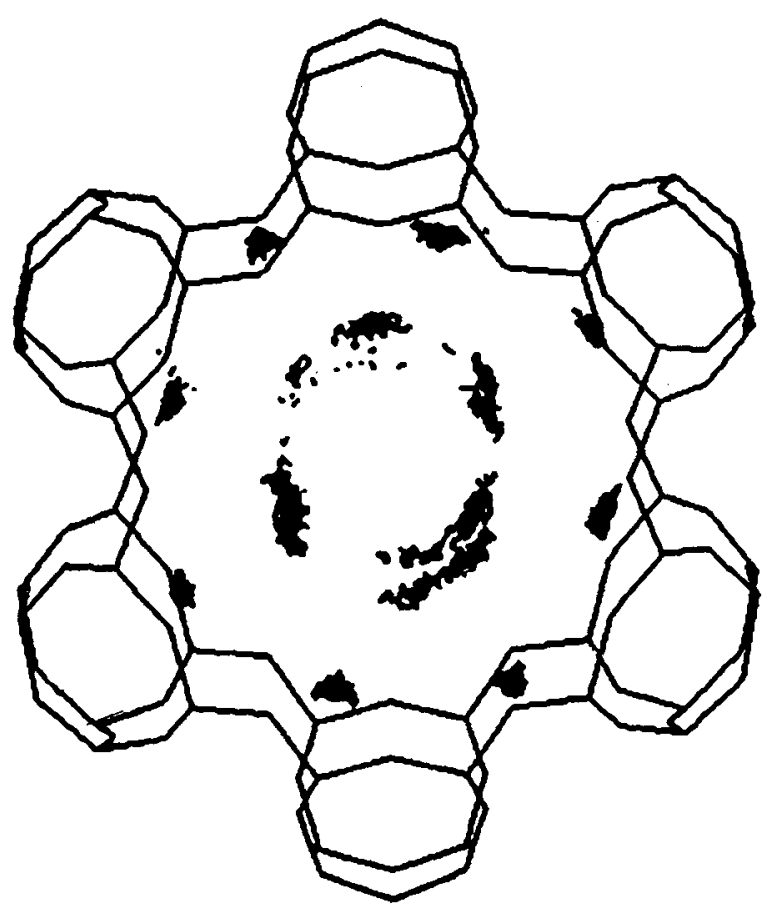

Figure 16. The trajectories of each of the thirteen argon atoms of an $\mathrm{Ar}_{13}$ cluster in zeolite $\mathrm{L}$ at $24 \mathrm{~K}$ have been shown. 
There are odd number of $\mathrm{C}-\mathrm{C}$ dihedral bonds present in hexane, octane and decane ( 3,5 and 7 respectively). For these three chains the central $\mathrm{C}-\mathrm{C}$ dihedral bond is numbered as 1 . The other dihedral bonds towards the right of the central bond are numbered in an increasing order $(2,3, \ldots$ etc). The bonds which are on the left of the central bond are once again numbered in an increasing order with primes $\left(2^{\prime}, 3^{\prime}, \ldots\right.$ etc). By symmetry the primed $\mathrm{C}-\mathrm{C}$ dihedral bonds are identical to the non-primed ones (i.e. $2 \equiv 2^{\prime}, 3 \equiv 3^{\prime}$ etc). There are four $\mathrm{C}-\mathrm{C}$ dihedral bonds in heptane. We have numbered the two central $\mathrm{C}-\mathrm{C}$ dihedral bonds as 1 and $1^{\prime}$ and the two terminal dihedral bonds as 2 and $2^{\prime}$ respectively. The trans and gauche populations of these bonds are listed in tables 9 and 10 for $n$-hexane to $n$-decane confined in zeolites $\mathrm{Y}$ and $\mathrm{A}$ respectively.

For clarity, the data presented in these tables are shown in figures 20 and 21 for zeolites $\mathrm{Y}$ and $\mathrm{A}$ respectively.

It is clear from figures 20 and 21 that there exists a pattern in the variation of gauche conformer population as one traverses from chain centre towards the chain end across the $n$-alkane series investigated here. It is observed that for $n$-hexane $(M=6)$ and $n$-heptane $(M=7)$ confined in both zeolites $Y$ and $A$, the probability of a terminal $\mathrm{C}-\mathrm{C}$ dihedral bond to remain in gauche form is higher than the non-terminal $\mathrm{C}-\mathrm{C}$ dihedral bonds. But from $M>7$ onwards ( $n$-octane and $n$-decane) the trend observed in both the zeolites is different from that observed for smaller

Table 5. Equilibrium thermodynamic properties of $n$-alkanes $\left(\mathrm{C}_{4} \mathrm{H}_{10}-\mathrm{C}_{10} \mathrm{H}_{22}\right)$ in zeolite $\mathrm{NaY}$ at a temperature of $400 \mathrm{~K}$ and sorbate concentration, $c=1 n$-alkane/ $\alpha$-cage.

\begin{tabular}{lccccccc}
\hline Molecule & $\begin{array}{c}U_{\mathrm{s}} \\
(\mathrm{kJ} / \mathrm{mol})\end{array}$ & $\begin{array}{c}U_{\mathrm{sz}} \\
(\mathrm{kJ} / \mathrm{mol})\end{array}$ & $\begin{array}{c}U_{\mathrm{sb}} \\
(\mathrm{kJ} / \mathrm{mol})\end{array}$ & $\begin{array}{c}U_{\mathrm{b}} \\
(\mathrm{kJ} / \mathrm{mol})\end{array}$ & $\begin{array}{c}U_{\mathrm{l}} \\
(\mathrm{kJ} / \mathrm{mol})\end{array}$ & $\begin{array}{c}U_{\mathrm{tot}} \\
(\mathrm{kJ} / \mathrm{mol})\end{array}$ & $\begin{array}{c}q_{\mathrm{st}} \\
(\mathrm{kJ} / \mathrm{mol})\end{array}$ \\
\hline $\mathrm{C}_{4} \mathrm{H}_{16}$ & -1.96 & -22.43 & - & 1.66 & 3.49 & -19.24 & 22.57 \\
$\mathrm{C}_{5} \mathrm{H}_{12}$ & -2.76 & -26.91 & -0.72 & 1.65 & 3.16 & -25.58 & 28.91 \\
$\mathrm{C}_{6} \mathrm{H}_{14}$ & -3.69 & -31.76 & -0.89 & 1.64 & 3.19 & -31.51 & 34.84 \\
$\mathrm{C}_{7} \mathrm{H}_{16}$ & -4.56 & -36.30 & -1.13 & 1.66 & 3.24 & -37.09 & 40.42 \\
$\mathrm{C}_{8} \mathrm{H}_{18}$ & -5.22 & -40.26 & -1.36 & 1.66 & 3.24 & -41.94 & 45.27 \\
$\mathrm{C}_{10} \mathrm{H}_{22}$ & -7.00 & -48.77 & -1.84 & 1.66 & 3.22 & -52.73 & 56.06 \\
\hline
\end{tabular}

Table 6. Equilibrium thermodynamic properties of $n$-alkanes $\left(\mathrm{C}_{4} \mathrm{H}_{10}-\mathrm{C}_{10} \mathrm{H}_{22}\right)$ in zeolite $\mathrm{NaCaA}$ at a temperature of $400 \mathrm{~K}$ and sorbate concentration, $c=1 n$-alkane/ $\alpha$-cage.

\begin{tabular}{lccccccc}
\hline Molecule & $\begin{array}{c}U_{\mathrm{ss}} \\
(\mathrm{kJ} / \mathrm{mol})\end{array}$ & $\begin{array}{c}U_{\mathrm{sz}} \\
(\mathrm{kJ} / \mathrm{mol})\end{array}$ & $\begin{array}{c}U_{\mathrm{nb}} \\
(\mathrm{kJ} / \mathrm{mol})\end{array}$ & $\begin{array}{c}U_{\mathrm{h}} \\
(\mathrm{kJ} / \mathrm{mol})\end{array}$ & $\begin{array}{c}U_{\mathrm{l}} \\
(\mathrm{kJ} / \mathrm{mol})\end{array}$ & $\begin{array}{c}U_{\text {tol }} \\
(\mathrm{kJ} / \mathrm{mol})\end{array}$ & $\begin{array}{c}q_{\mathrm{st}} \\
(\mathrm{kJ} / \mathrm{mol})\end{array}$ \\
\hline $\mathrm{C}_{4} \mathrm{H}_{10}$ & -1.45 & -51.24 & - & 1.65 & 3.41 & -47.63 & 50.96 \\
$\mathrm{C}_{5} \mathrm{H}_{12}$ & -2.46 & -61.40 & -0.73 & 1.65 & 3.08 & -59.86 & 63.19 \\
$\mathrm{C}_{6} \mathrm{H}_{14}$ & -3.01 & -71.86 & -0.90 & 1.65 & 3.23 & -70.89 & 74.22 \\
$\mathrm{C}_{7} \mathrm{H}_{16}$ & -2.39 & -81.43 & -1.07 & 1.66 & 3.53 & -79.70 & 83.03 \\
$\mathrm{C}_{8} \mathrm{H}_{18}$ & -3.20 & -90.48 & -1.08 & 1.68 & 3.62 & -89.46 & 92.79 \\
$\mathrm{C}_{10} \mathrm{H}_{22}$ & -6.68 & -111.39 & -1.41 & 1.67 & 3.53 & -114.28 & 117.61 \\
\hline
\end{tabular}



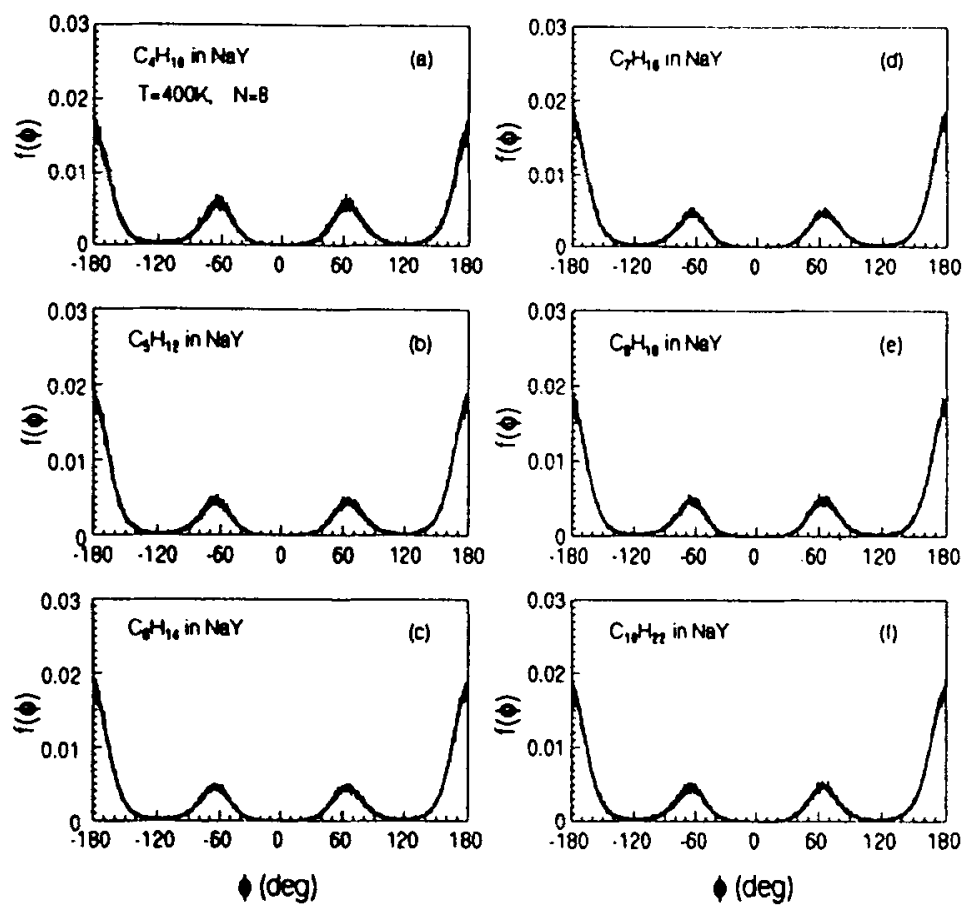

Figure 17. Dihedral angle distribution function $f(\phi)$ for $n$-alkanes ranging from $n$-butane $\left(\mathrm{C}_{4} \mathrm{H}_{10}\right)$ to $n$-decane $\left(\mathrm{C}_{10} \mathrm{H}_{22}\right)$ confined within the $\alpha$-cages of zeolite $\mathrm{NaY}$.

alkanes ( $n$-hexane and $n$-heptane). For octane and decane in zeolite $\mathrm{Y}$ it is observed that the probability of the central $\mathrm{C}-\mathrm{C}$ dihedral bond to be in gauche form is higher compared to its nearest neighbouring $\mathrm{C}-\mathrm{C}$ dihedral bonds, but it is less than the probability of a terminal C-C gauche bond (see figure 20). For example, probability of a central gauche bond for $n$-octane confined in zeolite $\mathrm{Y}$ is $35.6 \%$, which is higher than the corresponding probability for its nearest non-terminal $\mathrm{C}-\mathrm{C}$ dihedral bond 2 or $2^{\prime}$, $(32.0 \%)$, but less than that for a terminal C-C dihedral bond 3 or $3^{\prime}(39.6 \%$ ) (see table 9). Similar behaviour is also observed for $n$-decane in $\mathrm{Y}$. The probability of a gauche $\mathrm{C}-\mathrm{C}$ dihedral bond is maximum for $n$-decane at one end of the chain, 4 or $4^{\prime}(38.1 \%)$. Probability of the central C-C bond to be in gauche form is $36.8 \%$, which is less than that of the terminal C-C dihedral bonds $(38.1 \%)$, but higher than those of the other non-terminal dihedral bonds $(31 \cdot 1$ and $35.1 \%$ ). There is some difference in the conformations of different $\mathrm{C}-\mathrm{C}$ dihedral bonds for $n$-octane and $n$-decane confined in zeolite $\mathrm{A}$ as compared to those in zeolite $\mathrm{Y}$. For octane and decane confined in zeolite A the probability of a gauche $\mathrm{C}-\mathrm{C}$ dihedral bond is maximum at the centre of the chain rather than at the ends (see figure 21). For example, the probability of the central C-C dihedral bond to be gauche for $n$-octane confined in $\mathrm{A}$ is $49.7 \%$, which is higher than the probability for both terminal (46.6\%) as well as other non-terminal $\mathrm{C}-\mathrm{C}$ dihedral bonds $(41.0 \%)$ (see table 10). The probability of a gauche bond at the centre of the chain is even higher for $n$-decane confined in zeolite $A$. 

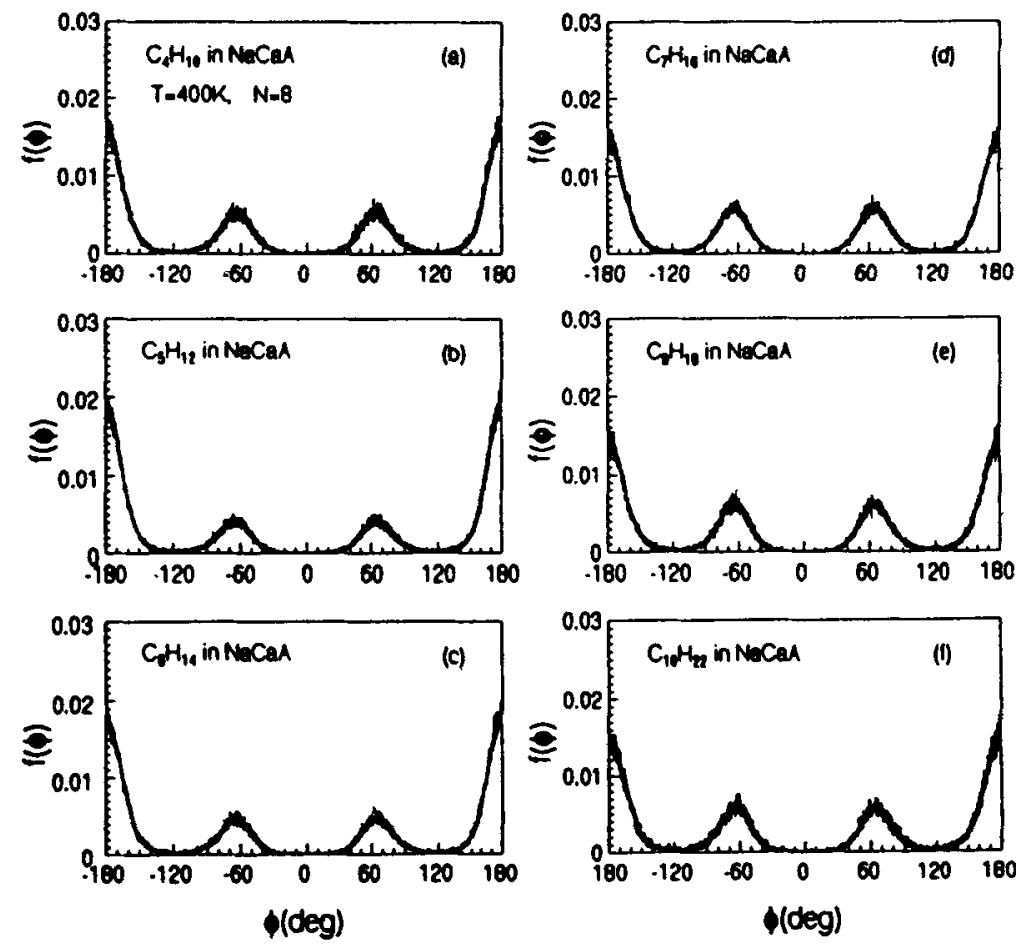

Figure 18. Dibedral angle distribution function $f(\phi)$ for $n$-alkanes ranging from $n$-butane $\left(\mathrm{C}_{\downarrow} \mathrm{H}_{14}\right)$ to $n$-decane $\left(\mathrm{C}_{13} \mathrm{H}_{22}\right)$ confined within the $\alpha$-cages of zeolite $\mathrm{NaCaA}$.

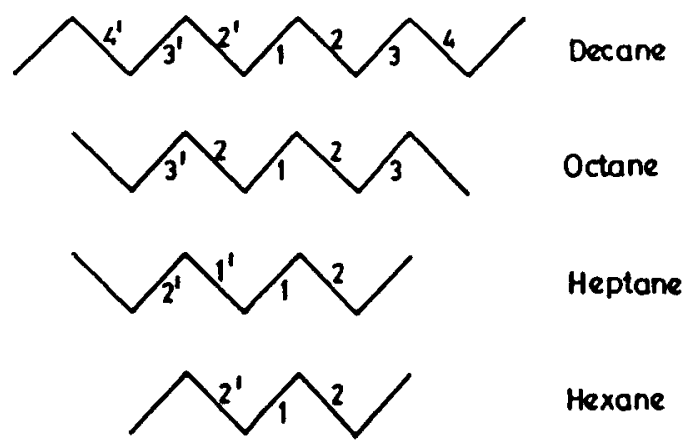

Figure 19. Schematic diagram representing the convention adopted in numbering the $\mathrm{C}-\mathrm{C}$ dihedral bonds along the chain for $n$-hexane $\left(\mathrm{C}_{6} \mathrm{H}_{14}\right)$ to $n$-decane $\left(\mathrm{C}_{10} \mathrm{H}_{22}\right)$.

It is clear from the above discussions that for long alkanes the effect of confinement on conformational properties is more pronounced when the molecules are confined in zeolite A. It is observed that the long $n$-alkane molecules exhibit a significant departure from linear shape when confined in zeolite $A$, which is reflected in large enhancement of the probability of finding a gauche bond at the centre of the chain 
Table 7. Average relative population of trans and gauche bonds for different $n$ alkanes $\left(\mathrm{C}_{4} \mathrm{H}_{10}\right.$ to $\left.\mathrm{C}_{10} \mathrm{H}_{22}\right)$ in zeolite $\mathrm{NaY}$ at a temperature of $400 \mathrm{~K}$ and sorbate concentration, $c=1 n$-alkane/ $\alpha$-cage.

\begin{tabular}{lcc}
\hline Molecule & \%trans & \%gauche \\
\hline $\mathrm{C}_{4} \mathrm{H}_{10}$ & 57.0 & 43.0 \\
$\mathrm{C}_{5} \mathrm{H}_{12}$ & 66.1 & 33.9 \\
$\mathrm{C}_{6} \mathrm{H}_{14}$ & 65.8 & 34.2 \\
$\mathrm{C}_{7} \mathrm{H}_{16}$ & 64.4 & 35.6 \\
$\mathrm{C}_{8} \mathrm{H}_{18}$ & 64.3 & 35.7 \\
$\mathrm{C}_{10} \mathrm{H}_{22}$ & 65.1 & 34.9 \\
\hline
\end{tabular}

Table 8. Average relative population of trans and gauche bonds for different $n$-alkanes $\left(\mathrm{C}_{4} \mathrm{H}_{\mathrm{ti}}-\mathrm{C}_{\mathrm{14}} \mathrm{H}_{22}\right)$ in zeolite $\mathrm{NaCaA}$ at a temperature of $400 \mathrm{~K}$ and sorbate concentration, $c=1 n$-alkane/ $\alpha$-cage.

\begin{tabular}{lcc}
\hline Molecule & \%trans & \%gauche \\
\hline $\mathrm{C}_{4} \mathrm{H}_{10}$ & 59.6 & 40.4 \\
$\mathrm{C}_{5} \mathrm{H}_{12}$ & 68.4 & 31.6 \\
$\mathrm{C}_{6} \mathrm{H}_{14}$ & 64.7 & 35.3 \\
$\mathrm{C}_{7} \mathrm{H}_{16}$ & 57.0 & 43.0 \\
$\mathrm{C}_{8} \mathrm{H}_{18}$ & 55.0 & 45.0 \\
$\mathrm{C}_{10} \mathrm{H}_{22}$ & 57.6 & 42.4 \\
\hline
\end{tabular}

Table 9. Percentage probability of remaining in trans or gauche form for every $\mathrm{C}-\mathrm{C}$ dihedral bond along the chain for different $n$-alkanes $\left(\mathrm{C}_{6} \mathrm{H}_{14}-\mathrm{C}_{10} \mathrm{H}_{22}\right)$ in zeolite $\mathrm{NaY}$ at a temperature of $400 \mathrm{~K}$ and sorbate concentration, $c=1 n$-alkane $/ \alpha$-cage.

\begin{tabular}{lccc}
\hline Molecule & Bond & \%trans & \%gauche \\
\hline \multirow{2}{*}{$\mathrm{C}_{6} \mathrm{H}_{14}$} & 1 & 72.4 & 27.6 \\
& 2 or $2^{\prime}$ & 62.5 & 37.5 \\
$\mathrm{C}_{7} \mathrm{H}_{16}$ & 1 or $1^{\prime}$ & 68.5 & 31.5 \\
& 2 or $2^{\prime}$ & 60.2 & 39.8 \\
$\mathrm{C}_{8} \mathrm{H}_{18}$ & 1 & 64.4 & 35.6 \\
& 2 or $2^{\prime}$ & 68.0 & 32.0 \\
& 3 or $3^{\prime}$ & 60.4 & 39.6 \\
$\mathrm{C}_{10} \mathrm{H}_{22}$ & 1 & 63.2 & 36.8 \\
& 2 or $2^{\prime}$ & 64.9 & 35.1 \\
& 3 or $3^{\prime}$ & 68.9 & 31.1 \\
& 4 or $4^{\prime}$ & 61.9 & 38.1 \\
\hline
\end{tabular}


Table 10. Percentage probability of remaining in trans or gauche form for every $\mathrm{C}-\mathrm{C}$ dihedral bond along the chain for different $n$-alkanes $\left(\mathrm{C}_{6} \mathrm{H}_{14}-\mathrm{C}_{10} \mathrm{H}_{22}\right)$ in zeolite $\mathrm{NaCaA}$ at a temperature of $400 \mathrm{~K}$ and sorbate concentration, $c=1 n$-alkane/ $\alpha$-cage.

\begin{tabular}{lccc}
\hline Molecule & Bond & \%trans & \%gauche \\
\hline & & & \\
$\mathrm{C}_{6} \mathrm{H}_{14}$ & 1 & 74.5 & 25.5 \\
& 2 or $2^{\prime}$ & 59.9 & 40.1 \\
$\mathrm{C}_{7} \mathrm{H}_{16}$ & 1 or $1^{\prime}$ & 65.1 & 34.9 \\
& 2 or $2^{\prime}$ & 48.8 & 51.2 \\
$\mathrm{C}_{8} \mathrm{H}_{18}$ & 1 & 50.3 & 49.7 \\
& 2 or $2^{\prime}$ & 59.0 & 41.0 \\
& 3 or $3^{\prime}$ & 53.4 & 46.6 \\
$\mathrm{C}_{10} \mathrm{H}_{22}$ & 1 & 41.5 & 58.5 \\
& 2 or $2^{\prime}$ & 51.3 & 48.7 \\
& 3 or $3^{\prime}$ & 65.4 & 34.6 \\
& 4 or $4^{\prime}$ & 64.2 & 35.8 \\
\hline
\end{tabular}

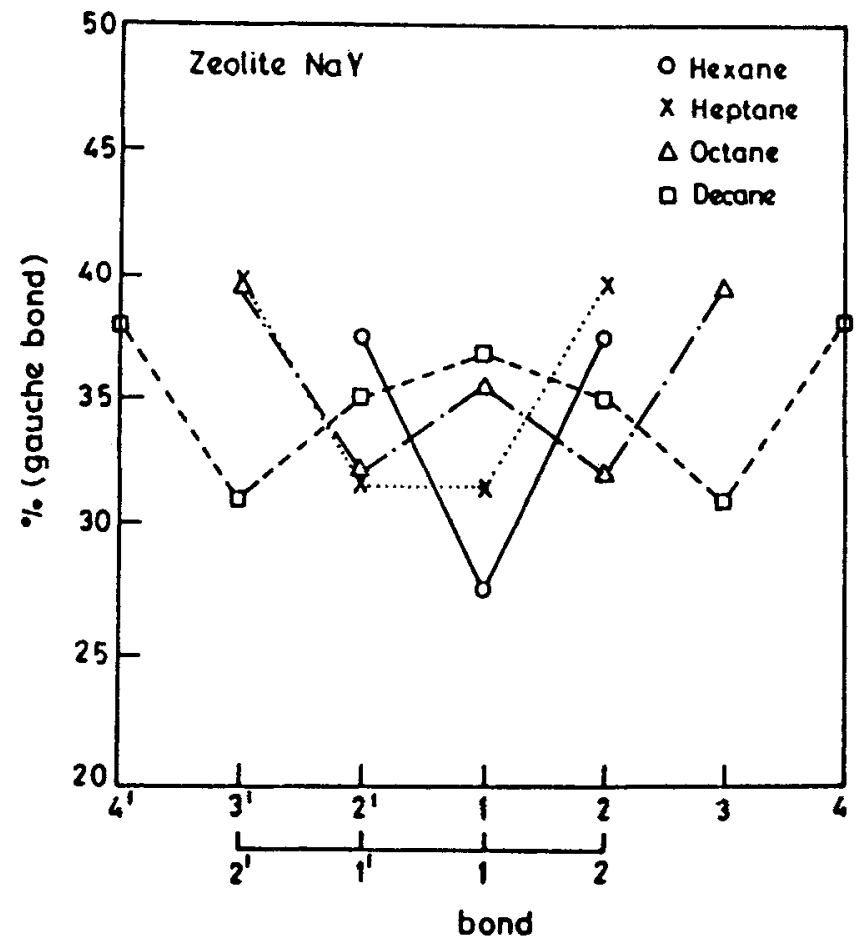

Figure 20. Percentage variation of gauche bonds along the chain for different $n$-alkanes $\left(\mathrm{C}_{6} \mathrm{H}_{14}\right.$ to $\left.\mathrm{C}_{10} \mathrm{H}_{22}\right)$ confined in zeolite $\mathrm{NaY}$. 
rather than towards the end. In figure 22 we have shown snapshots of actual conformation of an $n$-octane and $n$-decane molecule confined in zeolite $Y$ obtained from simulations.

These figures clearly demonstrate that in zeolite $\mathrm{Y}$, long $n$-alkane molecules are able to remain in stretched conformation, whereas in zeolite $A$, the molecules are much more coiled within the $\alpha$-cage. Although the sorbate-zeolite interaction energy, $U_{\mathrm{sz}}$, might play some role in determining the conformational properties of $n$-alkane molecules, but it seems to us that steric factor arising from the differences in topology of the voids in zeolites $\mathrm{Y}$ and $\mathrm{A}$ is mainly responsible for the observed differences in conformational properties of long $n$-alkanes confined in these two zeolites. The main difference between the voids in zeolites $\mathrm{Y}$ and $\mathrm{A}$ is the dimension of the windows separating two adjacent $\alpha$-cages. In zeolite $\mathrm{Y}, \alpha$-cages are interconnected in a tetrahedral fashion via 12-ring windows of approximately $8 \AA$ diameter. On the other hand, in zeolite $\mathrm{A}$ the $\alpha$-cages are octahedrally connected through 8-ring windows of much smaller dimension, $\sim 4.5 \AA$. Besides, the dimension of an $\alpha$-cage in zeolite $\mathrm{A}$ is also smaller than that in zeolite $\mathrm{Y}$. Because of large window diameter in zeolite $\mathrm{Y}$, long $n$-alkane molecules can stretch between two $\alpha$-cages quite comfortably. In figure $22 b$ it is shown how an $n$-decane molecule during simulation can occupy two adjacent $\alpha$-cages through the window connecting them. As a result, the steric influence on long $n$-alkanes within an $\alpha$-cage of zeolite $\mathrm{Y}$ is less, and, therefore, the molecules have more freedom to remain in stretched

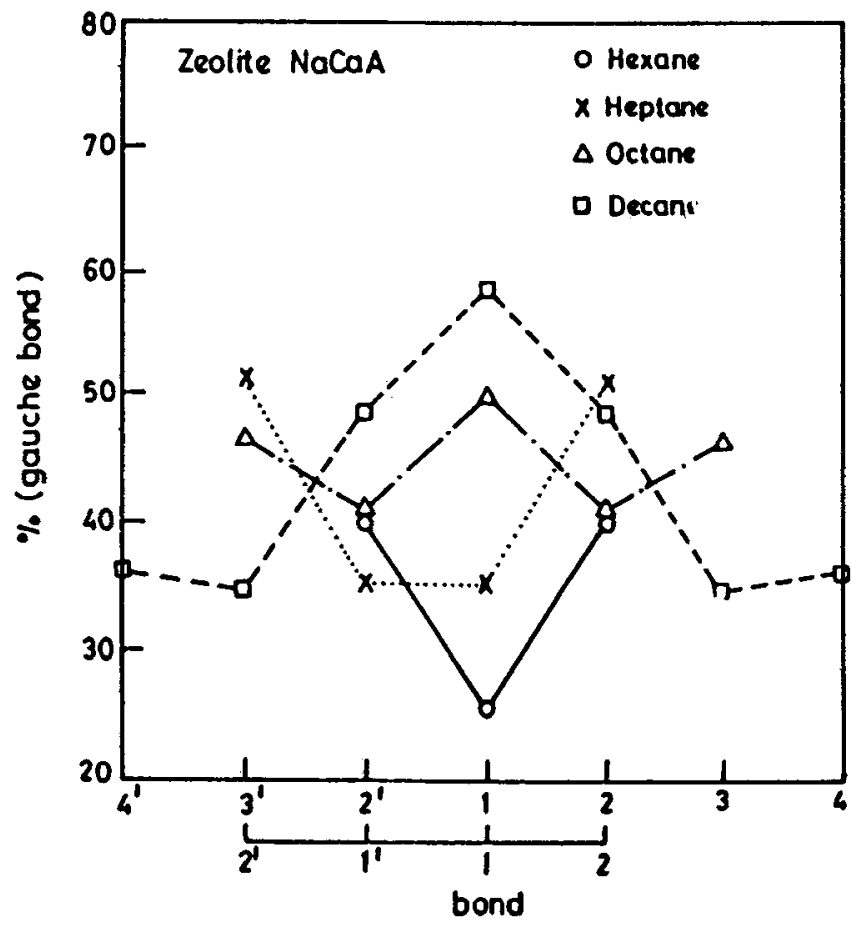

Figure 21. Percentage variation of gauche bonds along the chain for different $n$-alkanes $\left(\mathrm{C}_{6} \mathrm{H}_{14}\right.$ to $\left.\mathrm{C}_{10} \mathrm{H}_{22}\right)$ confined in zeolite $\mathrm{NaCaA}$. 

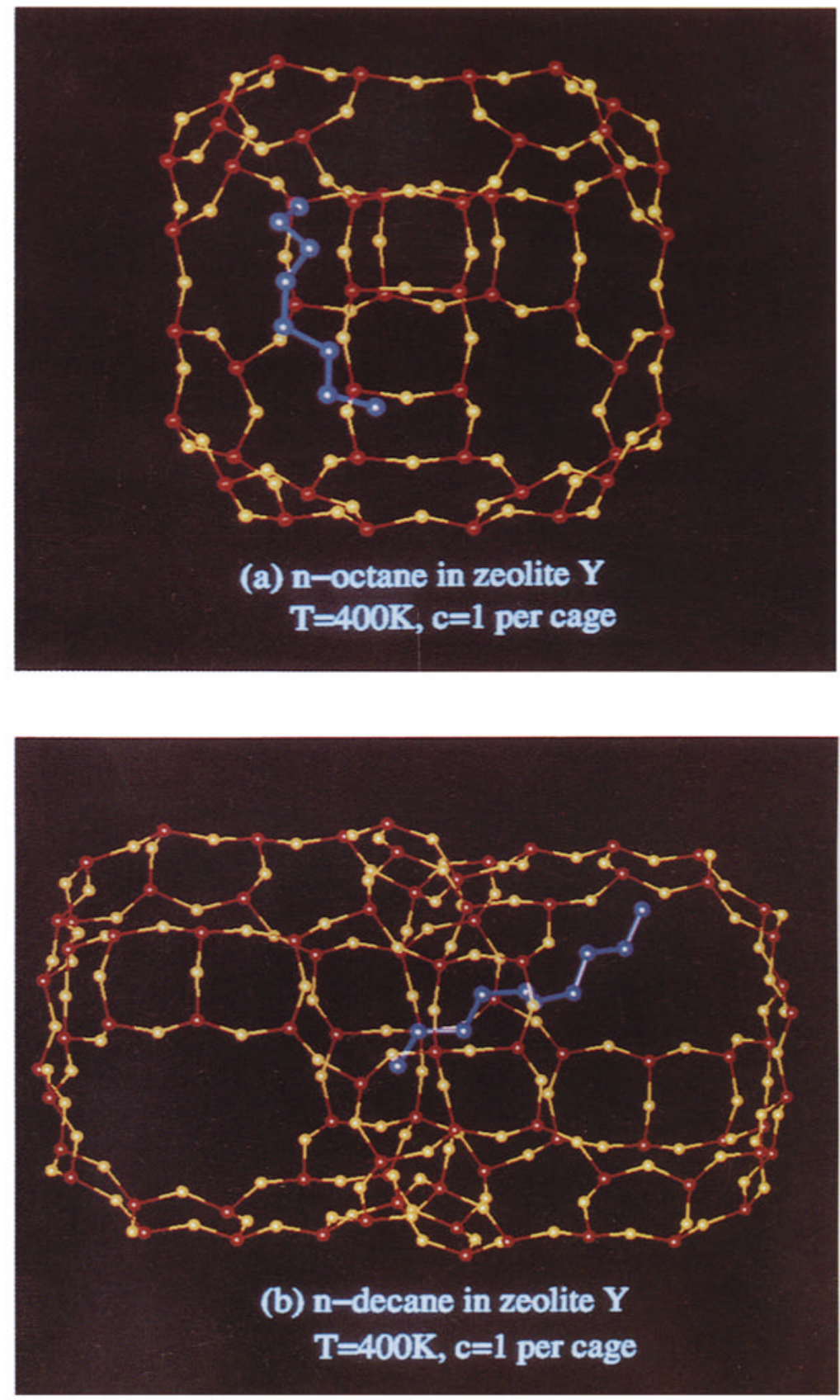

Figure 22. Snapshots of an (a) n-octane and (b) n-decane molecule confined within the $\alpha$-cages of zeolite NaY obtained from the MC simulation at $400 \mathrm{~K}$ and $c=1 n$-alkane/ $\alpha$-cage. 


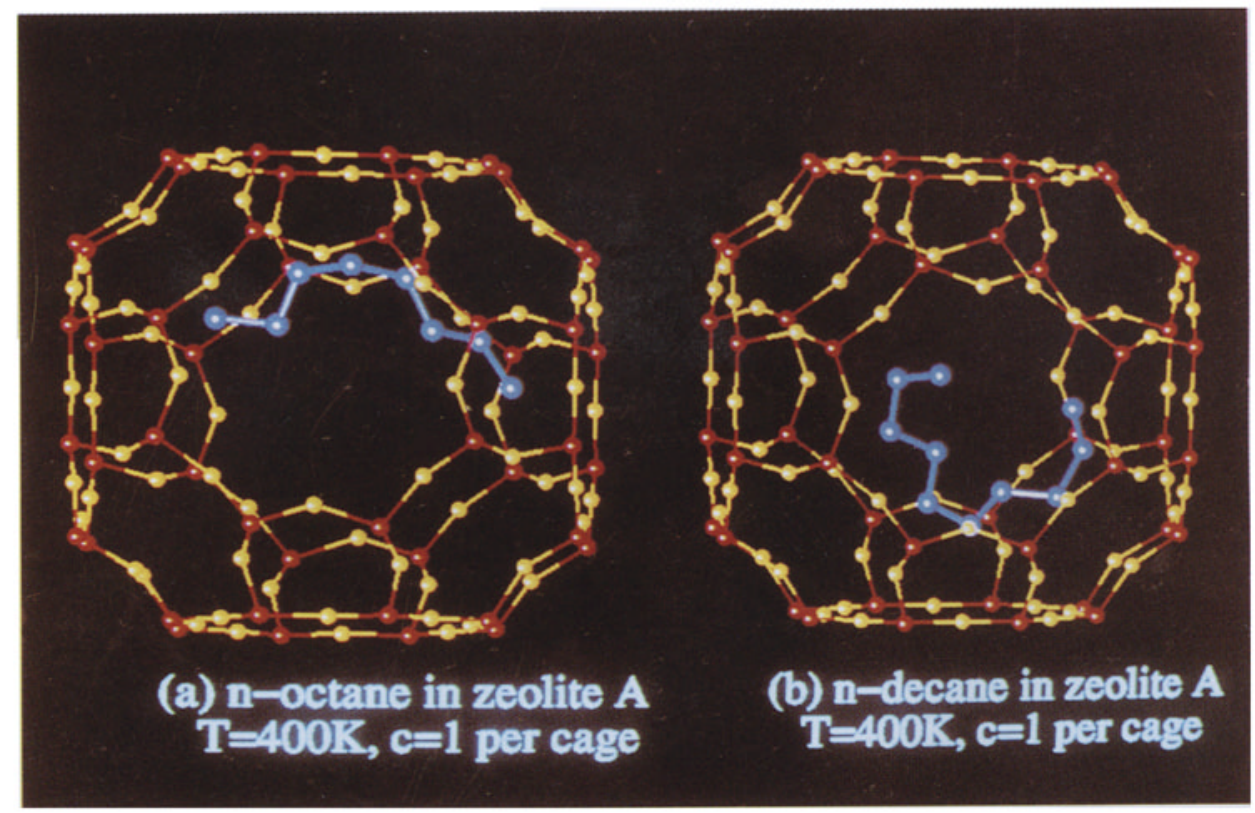

Figure 23. Snapshots of an (a) $n$-octane and (b) $n$-decane molecule confined within the $\alpha$-cages of zeolite $\mathrm{NaCaA}$ obtained from the $\mathrm{MC}$ simulation at $400 \mathrm{~K}$ and $c=1 n$-alkane $/ \alpha$-cage.
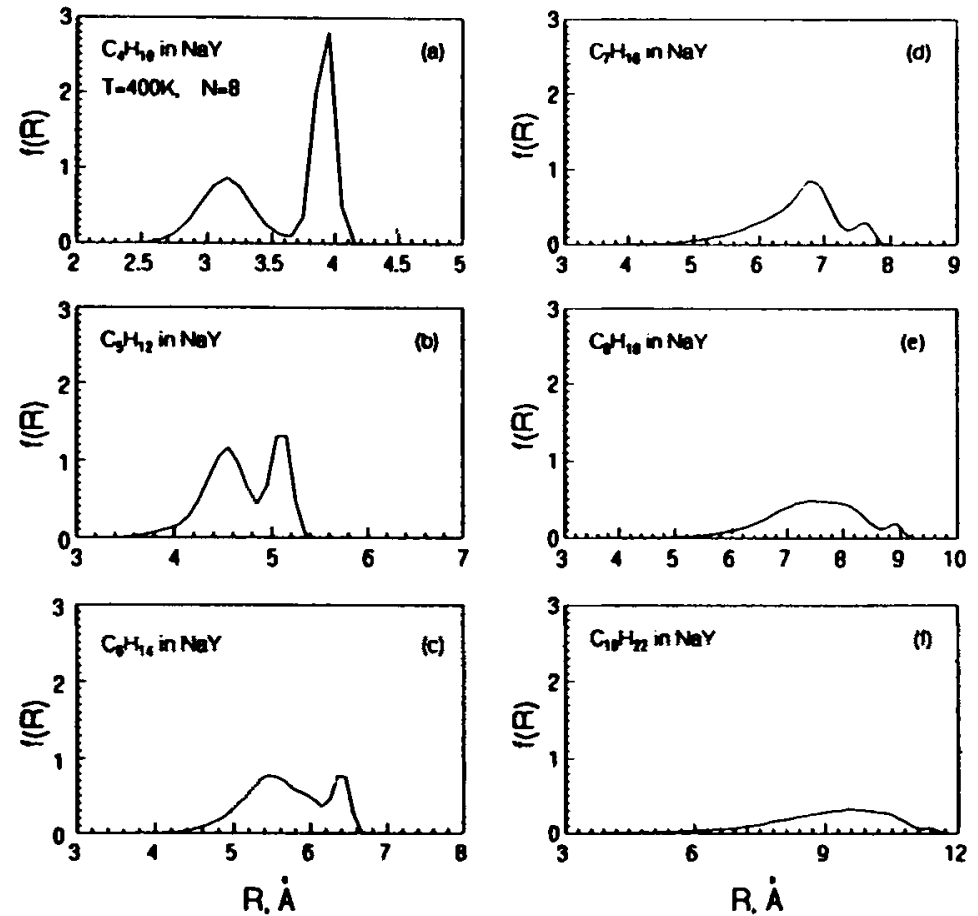

Figure 24. Distribution of end-to-end distance $f(R)$ of $n$-alkanes ranging from $n$-butane $\left(\mathrm{C}_{4} \mathrm{H}_{10}\right)$ to $n$-decane $\left(\mathrm{C}_{10} \mathrm{H}_{22}\right)$ confined within the $\alpha$-cages of zeolite NaY. 
conformation. On the other hand, due to smaller window dimension in zeolite A, long $n$-alkane molecules find it difficult to migrate or stretch through the windows. Therefore, the molecules remain mostly confined in an $\alpha$-cage. As a result, as the chain length increases the $n$-alkanes assume more and more coiled conformation with very large population of central $\mathrm{C}-\mathrm{C}$ gauche bond (see figure 23). Note that this type of confinement within the $\alpha$-cage of zeolite $\mathrm{A}$ is also observed for small chain such as $n$-butane at different concentrations and temperatures (Bandyopadhyay and Yashonath 1997).

Figures 24 and 25 show the distribution of end-to-end distance $f(R)$ of different $n$-alkane molecules starting from $n$-butane to $n$-decane in zeolites $\mathrm{Y}$ and A respectively.

End-to-end distance $(R)$ of an $n$-alkane molecule with chain length $M$ is calculated as the distance between the first and the $M$ th methyl groups (i.e. the two end methyl groups in a chain). This distribution gives an estimation of the change in conformations of $n$-alkane molecules with increase in chain length. The distribution for $n$-butane $(M=4)$ in both zeolites $Y$ and A consists of two peaks. A sharp peak of high intensity is observed at an end-to-end distance $R \sim 3.9 \AA$, which corresponds to trans $n$-butane. A broad peak, with much lower intensity, is observed around $R=3 \cdot 1 \AA$, which corresponds to the gauche $n$-butane. In both zeolites $\mathrm{Y}$ and $\mathrm{A}$ as the alkane chain length is increased intensity of the peak, corresponding to the trans conformation, decreases and that corresponding to the gauche conformation increases. In zeolite $\mathrm{Y}$, up to $M=8$, the curves consist of two peaks, which suggest
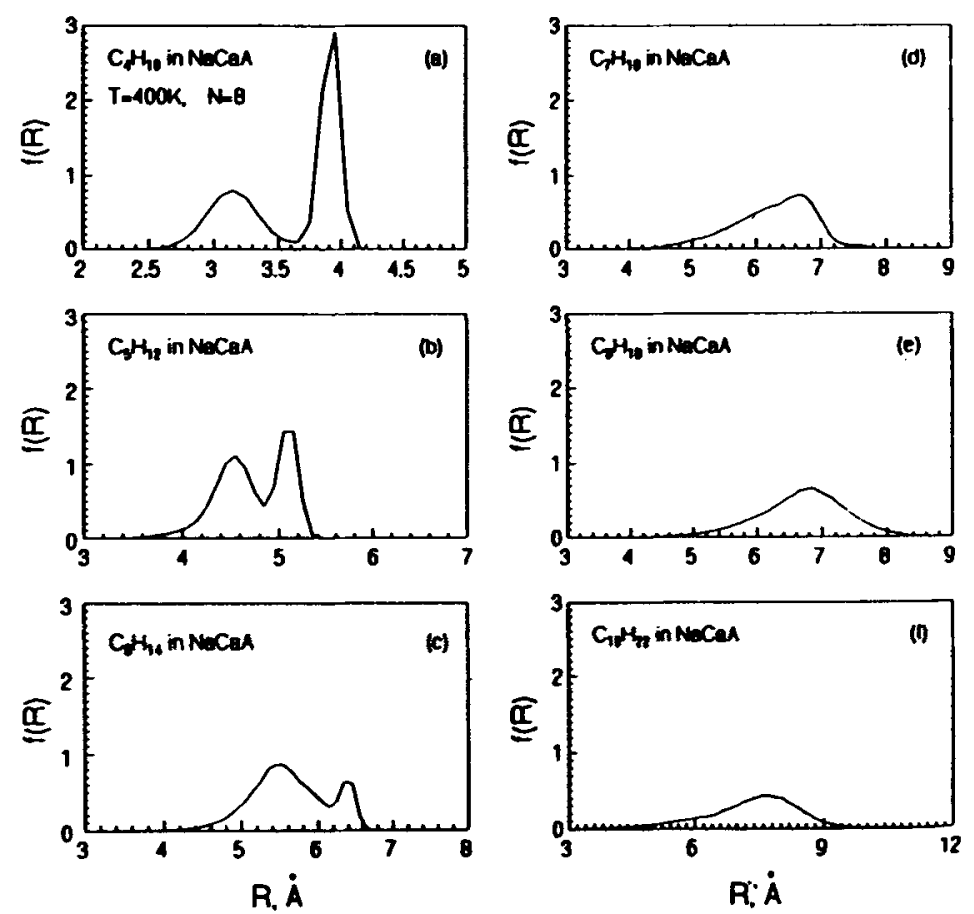

Figure 25. Distribution of end-to-end distance $f(R)$ of $n$-alkanes ranging from $n$-butane $\left(\mathrm{C}_{4} \mathrm{H}_{10}\right)$ to $n$-decane $\left(\mathrm{C}_{10} \mathrm{H}_{22}\right)$ confined within the $\alpha$-cages of zeolite NaCaA. 
that although population of gauche bonds has increased but still the molecules remain in stretched conformation. In zeolite $A$, for $M \geq 7$, the distribution becomes unimodal and the peak appears at much lower value of $R$ compared to that observed in zeolite $\mathrm{Y}$. For example, for $n$-decane in zeolite $\mathrm{A}$, the peak in the distribution is at $7.5 \AA$ whereas in zeolite $Y$, the maxima in the peak appears around $10 \AA$. In fact distribution is almost zero in zeolite $\mathrm{A}$ for $R>9 \AA$. Similar trend is also observed for $n$-heptane and $n$-octane. This shift of maxima towards lower values of $R$ for long $n$-alkanes $(M \geq 7)$ confined in zeolite $\mathrm{A}$, proves that conformations of these molecules deviate significantly from linear shape, which is a consequence of large enhancement of central gauche bonds.

\section{Conclusions}

It is seen that the geometry and the energy of the clusters confined in zeolite $\mathrm{NaCaA}$ are strongly influenced by the symmetry of the cavity in which it is confined. A plot of the $\Delta U / \Delta n$ for various $n$ for the confined clusters suggests the existence of magic numbers among confined clusters. The magic numbers for the confined clusters are different from those encountered for free clusters. This is the first time that evidence for the possible existence of magic numbers for the confined clusters has been obtained. It is, however, necessary to carry out a more thorough search to ensure that the global minimum has been obtained for every cluster size. Variation of the melting temperature with $n$ and other relevant properties will be helpful to decide about the existence or otherwise of the magic numbers.

Simulated annealing is a method employed widely to perform global optimization of complex systems. In this method, the system is cooled slowly and it is hoped that the system reached the global minimum. In the present work, we have chosen to start with any arbitrary configuration and slowly increase the temperature. As the temperature is increased the system begins to sample the phase space more efficiently, and it is found that at some temperature the system falls from the local minimum into the global minimum or an energy close to it. It is necessary to explore this method for other complex problems such as the travelling salesman, etc.

We have compared the conformational behaviour of long $n$-alkanes confined in zeolites $\mathrm{NaY}$ and $\mathrm{NaCaA}$. It appears that conformational properties of $n$-alkanes in zeolite $\mathrm{A}$ are significantly different from those in zeolite $\mathrm{Y}$. This difference is more pronounced for $M \geq 8$. It is observed that up to $M=7$, probability of a central gauche bond is less than that of the terminal $\mathrm{C}-\mathrm{C}$ dihedral bonds in both zeolites $\mathrm{Y}$ and $\mathrm{A}$. But in zeolite $\mathrm{A}$ for $M \geq 8$, it is observed that probability of a central gauche bond is highest among all the $\mathrm{C}-\mathrm{C}$ dihedral bonds. This shows that in zeolite A, long $n$-alkane molecules deviate significantly from linear conformation. This effect is much less pronounced in zeolite $\mathrm{Y}$. We attribute this difference in conformational properties in zeolites $\mathrm{Y}$ and $\mathrm{A}$ to the difference in the dimension of the windows connecting two $\alpha$-cages. In zeolite $\mathrm{Y}$ windows are of much wider dimension ( $8 \AA$ diameter), compared to those in zeolite $\mathrm{A}$ ( $4.5 \AA$ diameter). As a result of large window diameter a long $n$-alkane molecule can easily migrate between the $\alpha$-cages as well as can stretch itself within two $\alpha$-cages through the window, and therefore can remain in a conformation not much different from a 
linear one. But narrow windows present in zeolite A do not allow a long-chain molecule to pass through it. As a result, the molecules mostly remain coiled within an $\alpha$-cage of zeolite $\mathrm{A}$. Large increase in sorbate-zeolite interaction energy in zeolite $\mathrm{A}$ with increase in chain length also influences the conformational properties of long $n$-alkane molecules. Shift of the maxima in end-to-end distance distribution towards lower value of $R$ for long $n$-alkanes confined in zeolite $\mathrm{A}$ also suggests significant deviation of the molecules from linear shape.

\section{References}

Adams J E and Stratt R M 1990a J. Chem. Phys. 931332

Adams J E and Stratt R M 1990b J. Chem. Phys. 931358

Adams J E and Stratt R M 1990c J. Chem. Phys. 931632

Allen M P and Tildesley D J 1987 Computer simulation of liquids (Oxford: Clarendon Press)

Bandyopadhyay S and Yashonath S $1997 \mathrm{~J}$. Phys. Chem. (communicated)

Beck T L and Marchioro II T L 1990 J. Chem. Phys. 931347

Berry R S 1994 J. Phys. Chem. 986910

Berry R S and Cheng H-P 1992 Physics and chemistry of finite systems: From clusters to crystals (Kluwer Academic Pub.) Vol. I, p. 277

Chitra R and Yashonath S 1997 J. Phys. Chem. B101 389

Cheng H-P and Berry R S 1992 Phys. Rev. A45 7969

Chmelka B F, Raftery D, McCormick A V, de Menorval L C, Levine R D and Pines A 1991 Phys. Rev. Lett. 66580

Davis H L, Jellinek J and Berry R S 1987 J. Chem. Phys. 866456

Etters R D and Kaelberer J 1977 J. Chem. Phys. 665112

Fitch A N, Jobic H and Renouprez A 1986 J. Phys. Chem. 901311

Frantz D D 1995 J. Chem. Phys. 1023747

Frenkel D, Mooij G C A M and Smit B 1992 J. Phys.: Condens. Matter 43053

Harris J and Rice S A 1988 J. Chem. Phys. 881298

Heink W, Karger J, Pleifer H, Salverda P, Datema K P and Nowak A 1992 J. Chem. Soc. Faraday Trans. 88515

Henson N J, Cheetham A K, Peterson B K, Pickett S D and Thomas J M 1993 J. Computer-Aided Mater. Design $14 \mathrm{I}$

Hernandez E and Catlow C R A 1995 Proc: R. Soc: London A448 143

Hoare M R and Pal P 1970 Nature 2305

Honeycutt J D and Andersen H C 1987 J. Phys. Chem. 914950

Inglesfield E J 1982 in Computer simulation of solids (eds) C R A Catlow and W C Mackrodt (Berlin: Springer Verlag)

Jorgensen W L, Madura J D and Swenson C J 1984 J. Am. Chem. Siא. 1066638

June R L, Bell A T and Theodorou D N $1990 \mathrm{~J}$. Phys. Chem. 941508

June R L, Bell A T and Theodorou D N 1992 J. Phys. Chem. 961051

Karger J and Ruthven D M 1992 Diffusion in zeolites and other microporous solids (New York: John Wiley \& Sons)

Karger J, Pfeifer H, Rauscher M and Walter A 1980 J. Chem. Soc. Faraday Trans. I 76717

Kirkpatrick K S, Gelatt C D and Vecchi M P 1983 Science 220671

Kiselev A V and Du P Q 1981 J. Chem. Soc. Faraday Trans. II 77 I

Kunz R E and Berry R S 1993 Phys. Rev. Lett. 713987

Laso M, de Pablo J J and Suter U W 1992 J. Chem. Phys. 962817

Li F-Y and Berry R S 1995a J. Phys. Chem. 992459

Li F-Y and Berry R S 1995b J. Phys. Chem. 9915557

Maginn E J, Bell A T and Theodorou D N 1995 J. Phys. Chem. 992057

Metropolis N, Rosenbluth A, Rosenbluth M, Teller A and Teller E 1953 J. Chem. Phys. 211087

Mooij G C A M, Frenkel D and Smit B 1992 J. Phys: Condens. Matter 4 L255

Nauchitel V V and Pertsin A J 1980 Mol. Phys. 401341

de Pablo J J, Laso M and Suter U W 1992 J. Chem. Phys. 966157 
de Pablo J J, Laso M, Suter U W and Cochran H D 1993 Fluid Phase Equilib. 83323

Pluth J J and Smith J V 1980 J. Am. Chem. Soc. 1024704

Quirke N and Sheng P 1984 Chem. Phys. Lett. 11063

Richards R E and Rees L V C 1987 Langmuir 3335

Rosenbluth M N and Rosenbluth A W 1955 J. Chem. Phys. 23356

Santikary P, Yashonath S and Ananthakrishna G 1992 J. Phys. Chem. 9610469

Seeley G and Keyes T 1989 J. Chem. Phys. 915581

Siepmann J I and Frenkel D 1992 Mol. Phys. 7559

Siepmann J I, Karaborni S and Smit B 1993a Nature 365330

Siepmann J I, Karaborni S and Smit B 1993b J. Am. Chem. Soc. 1156454

Smit B and Siepmann J I 1994a J. Phys. Chem. 988442

Smit B and Siepmann J I 1994b Science 2641118

Thamm H 1987 Zeolites 7341

Van der Ploeg P and Berendsen H J C 1982 J. Chem. Phys. 763271

Wright P A, Thomas J M, Cheetham A K and Nowak A K 1985 Nature 318611 